University of Louisville

ThinkIR: The University of Louisville's Institutional Repository

Electronic Theses and Dissertations

8-2006

\title{
Significance of orientation and determination of cummulative damage measures during cyclic testing of human thoracolumbar spine.
}

Sai Yalla

University of Louisville

Follow this and additional works at: https://ir.library.louisville.edu/etd

\section{Recommended Citation}

Yalla, Sai, "Significance of orientation and determination of cummulative damage measures during cyclic testing of human thoracolumbar spine." (2006). Electronic Theses and Dissertations. Paper 1611.

https://doi.org/10.18297/etd/1611

This Master's Thesis is brought to you for free and open access by ThinkIR: The University of Louisville's Institutional Repository. It has been accepted for inclusion in Electronic Theses and Dissertations by an authorized administrator of ThinkIR: The University of Louisville's Institutional Repository. This title appears here courtesy of the author, who has retained all other copyrights. For more information, please contact thinkir@louisville.edu. 
SIGNIFICANCE OF ORIENTATION AND DETERMINATION OF

CUMMULATIVE DAMAGE MEASURES DURING CYCLIC TESTING OF HUMAN THORACOLUMBAR SPINE

\author{
By \\ Sai Vikas Yalla \\ B.E, Madras University, India (2004)
}

\begin{abstract}
A Thesis
Submitted to the Faculty of the

Graduate School of the University of Louisville

in partial Fulfillment of the Requirements

for the Degree of
\end{abstract}

MASTERS OF SCIENCES

Department of Industrial Engineering

University of Louisville

Louisville, Kentucky

August 2006 
SIGNIFICANCE OF ORIENTATION AND DETERMINATION OF CUMMULATIVE DAMAGE MEASURES DURING CYCLIC TESTING OF HUMAN THORACOLUMBAR SPINE

\author{
By \\ Sai Vikas Yalla \\ B.E., Madras University, India (2004) \\ A Thesis Approved on
}

July 18, 2006

By the following Thesis Committee:

Dr. Naira H. Campbell Kyureghyan, Thesis Director

Department of Industrial Engineering

Dr. Michael J. Voor

Department of Orthopedic Surgery

Dr. William E. Biles

Department of Industrial Engineering 


\section{DEDICATION}

This thesis is dedicated to my parents

Mr. Jagannadha Rao Yalla

And

Mrs. Venkata Lakshmi Kommireddi

my Grandparents and all my well wishers, for their guidance support and love. 


\section{ACKNOWLEDGMENTS}

I would like to thank my professor, Dr. Naira Campbell-Kyureghyan, for her valuable guidance and utmost patience. I would like to thank Dr. Michael J. Voor for his invaluable comments and suggestions. I would like to thank Dr. William E. Biles for serving on my thesis committee. I would also like thank Mr. Gary E. Graf for assistance in making the loading fixture and Mr. Robert L. Burden for his assistance with the MTS. Finally, I would like to thank Ramakrishna Mulpuri and David Burnett for data computation and each and every one who helped with this thesis. 


\section{ABSTRACT \\ SIGNIFICANCE OF ORIENTATION AND DETERMINATION OF CUMMULATIVE DAMAGE MEASURES DURING CYCLIC TESTING OF HUMAN THORACOLUMBAR SPINE}

Sai Vikas Yalla

July 18,2006

Determining the mechanical properties of the spine is a significant step in understanding the behavior of the spine under normal conditions. Although a limited amount of data for cyclic loading is currently available, the tests are not completely documented and the loads, spine segment positioning, and frequency are not representative of those typically found during normal activities. The purpose of this study is to develop an understanding of the relationship between loads and the development of fatigue failure in thoracolumbar motion segments.

Motion segments separated from human cadaveric spine were tested in two series. Compression series applied a pure compression load quasi-statically in the neutral position. The load was increased and the specimen was observed to determine failure. Motion segments were also tested without orientation (axially aligned). The difference of failure stress was analyzed to see the influence of spine segment positioning on the mechanical properties of the spine. $50 \%$ of the failure stress from neutrally aligned motion segments was used to define the loading for cyclic compression tests. Flexion series of testing applied a maximum bending moment on the motion segment in neutral 
position. $50 \%$ of maximum bending moment was used to define the loading for cyclic bending tests. In order to simulate typical work conditions, the load was applied at two frequencies, $0.2 \mathrm{~Hz}$ and $0.1 \mathrm{~Hz}$.

Quantitative information on damage prediction using creep and energy dissipation as measures was obtained. Cyclic stress-strain data were collected to quantify the material properties and how they change with accumulated damage. The difference in behavior for two loading frequencies was studied. It was observed that a vast majority of creep occurred during the first two hours of cycling. The rate of change of creep gradually decreased over time and eventually became relatively constant. A linear increase of energy density was observed over the 8 hour period. Rate of change of the energy density was relatively constant.

The results from the tests show that mechanical properties of the disc depend on the orientation of the motion segments at neutral angle. Results also suggest that energy dissipation could be potentially a good damage measure unlike creep. 


\section{TABLE OF CONTENTS}

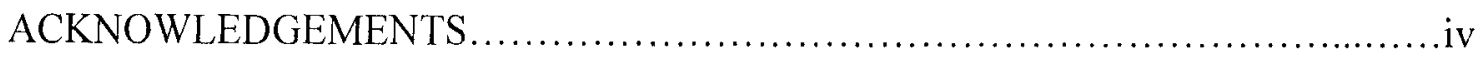

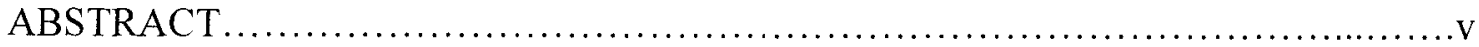

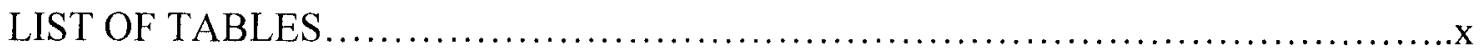

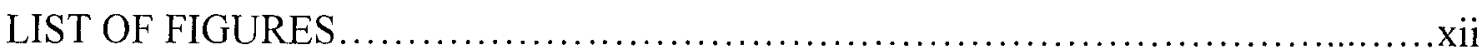

CHAPTER

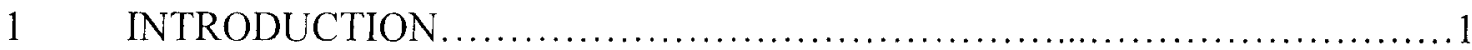

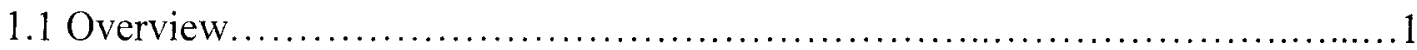

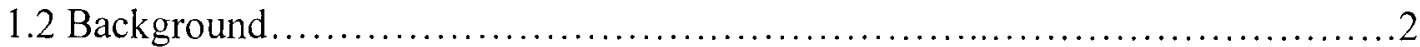

1.3 Literature Review................................................................

1.3.1 Anatomy of the Spine ...............................................

1.3.1.1 Vertebrae...................................................

1.3.1.2 Vertebral Endplates..........................................

1.3.1.3 Intervertebral Disc...........................................

1.3.2 Prior Research...................................................6

1.4 Limitations of Prior Research....................................................

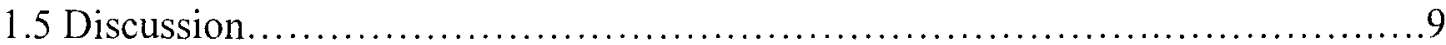

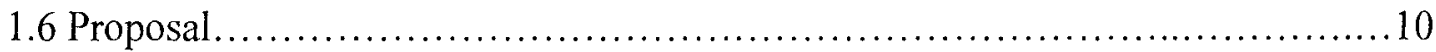

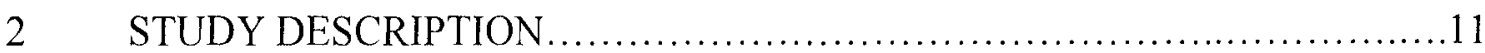

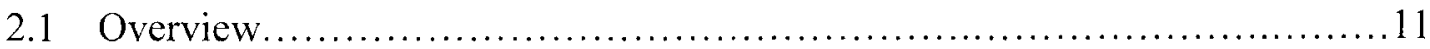

2.1.1 Significance of Orientation.....................................11

2.1.2 Segment Orientation............................................ 12 


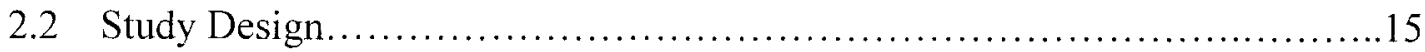

2.2.1 Compression Series of Testing...................................17

2.2.2 Flexion Series of Testing ....................................... 18

$2.3 \quad$ Material..................................................................

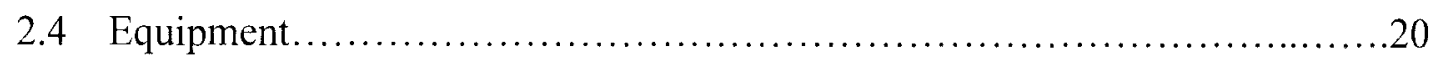

2.4.1 Material Testing System.......................................20

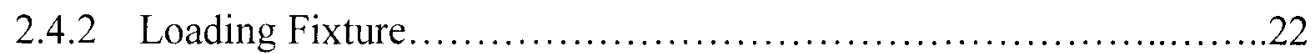

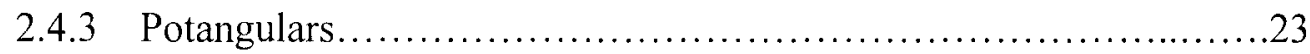

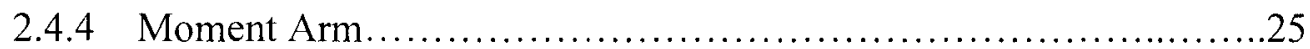

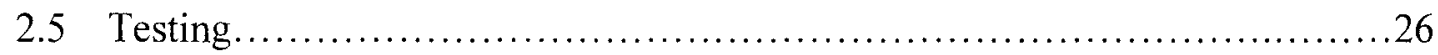

2.5.1 Preload ...............................................................

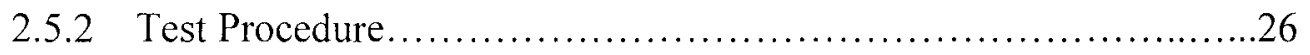

2.5.2.1 Compression Series.......................................27

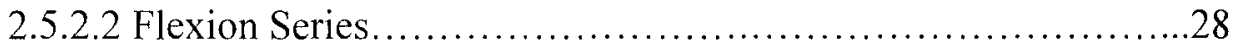

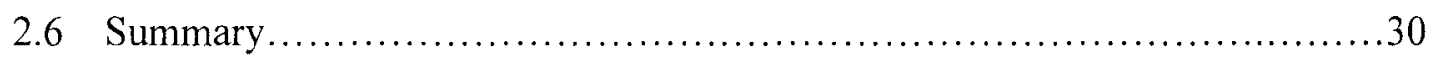

3 RESULTS AND ANALYSIS

3.1 Definitions...................................................................

3.2 Ultimate Compression Failure Test Results.................................32

3.3 Cyclic Axial Compression Test Results.......................................37

3.3.1 Cyclic Axial Compression Test Results at $0.1 \mathrm{~Hz} \ldots \ldots \ldots \ldots \ldots \ldots \ldots \ldots . . . \ldots 38$

3.3.2 Cyclic Axial Compression Test Results at $0.2 \mathrm{~Hz} . \ldots \ldots \ldots \ldots \ldots \ldots \ldots . . . . . . . .41$

3.4 Ultimate Bending Test Results...........................................44 
3.5 Cyclic Bending Test Results............................................45

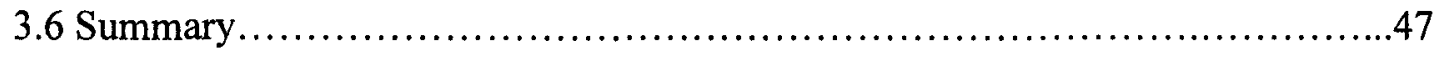

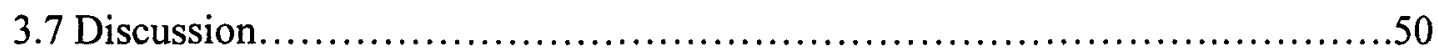

3.7.1 Influence of Orientation...........................................50

3.7.2 Influence of Frequency........................................... 51

3.7.3 Creep as Damage Measure ..........................................52

3.7.4 Energy Dissipation as Damage Measure..................................53

3.7.5 Ultimate Bending Tests.........................................53

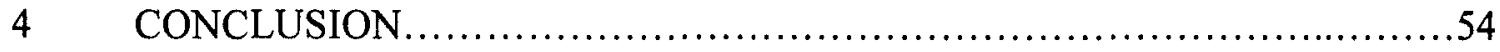

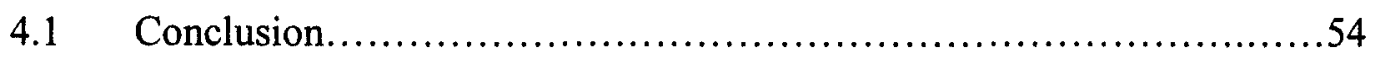

4.2 Limitations and Future Research..................................55

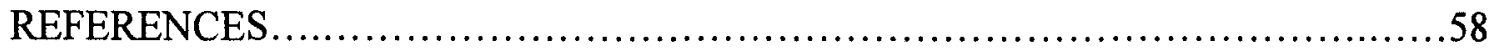

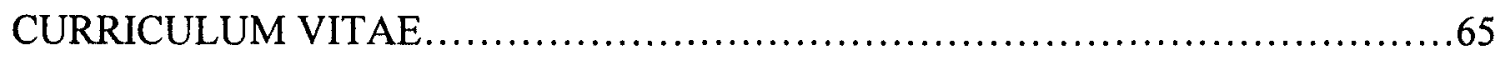




\section{LIST OF TABLES}

Table 1.1 Loading frequencies and failure criteria used in prior research.............8

Table 2.1 Description of segment orientation from previous studies..............13

Table 2.2 Harrison angles for the thoracolumbar region..........................14

Table $2.3 \quad$ Test series and groups........................................... 17

Table $2.4 \quad$ Testing parameters..................................................19

Table 2.5 Description of Anterior and Posterior heights of the vertebrae and disc

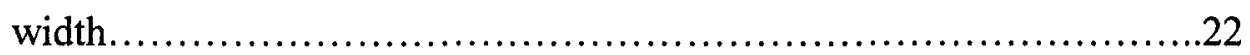

Table 3.1 Description of age, gender and resultant orientation angles of the potangulars for the specimens tested for compression failure.............33

Table 3.2 Summary of test results of all ultimate compression failure tests tabulated with respect to the specimen number and level.......................36

Table 3.3 Summary of test results of cyclic compression tests at $0.1 \mathrm{~Hz}$ tabulated with respect to the specimen number and level.

Table 3.4 Summary of test results of cyclic axial compression at $0.2 \mathrm{~Hz}$ tabulated with respect to the specimen and level....

Table 3.5 Summary of test results of ultimate flexion tests tabulated with respect to the specimen and level. 45

Table 3.6 Summary of the resultant angular deformation of the disc at 4900 cycles and end of the test in cyclic bending tests. .46 
Table 3.7 Summary of spine motion segments tested, the average age of the specimens tested, number of males, number of females and total number of spines tested................................................ 47 


\section{LIST OF FIGURES}

Figure 1.1 Lateral and posterior views of the spinal column (Adopted form Atlas of Human Anatomy by Frank Netter) ...................................

Figure 1.2 Division of vertebrae (adopted from Bogduk N, "Clinical Anatomy of the Lumbar Spine", 1997)...............................................4

Figure 1.3 Concentric layers of annulus fibrosus and orientation of collagen fibers of intervertebral disc (adapted from White and Panjabi, "Clinical Biomechanics of the Spine", 1990)...............................6

Figure 2.1 Schematic representation of motion segment.........................15

Figure 2.2 Schematic Block Diagram of the Experimental Design..................16

Figure 2.3 Schematic Diagram of Ultimate Compression Test.....................18

Figure 2.4 Schematic Diagram of Cyclic Axial Compression Test..................18

Figure 2.5 Schematic Diagram of the Loading Fixture and its detachable sections...21

Figure 2.6 Schematic diagram of the adapter plates of potangular...................24

Figure 2.7 Schematic representation of Moment Arm..........................25

Figure 3.1 Behavior of Force $(\mathrm{N})$ and disc deformation $(\mathrm{mm})$ of one of the motion segments tested for ultimate compression...........................34

Figure 3.2 Comparison of the effect of segment orientation on failure stress for the six specimens, 2 from each spine tested with and without orientations....35

Figure 3.3 Behavior of strain rate over the 8 hour period in one of the motion segment tested for cyclic axial compression test at $0.1 \mathrm{~Hz} \ldots \ldots \ldots \ldots \ldots . \ldots 38$ 
Figure 3.4 Behavior of energy density $\left(\mathrm{KJ} / \mathrm{mm}^{3}\right)$ over 8 hour time period in cyclic axial compression tests at $0.1 \mathrm{~Hz}$ .41

Figure 3.5 Creep of the intervertebral disc during cyclic axial compression test at 0.2 $\mathrm{Hz}$. .42

Figure 3.6 Behavior of mean energy density versus time $(\mathrm{Hr})$ in cyclic axial compression tests at $0.2 \mathrm{~Hz}$.

Figure 3.7 Creep in terms of angular deformation (deg) versus time ( $\mathrm{Hr})$ for one of the motion segments tested for cyclic bending at $20 \mathrm{Nm}$. 46

Figure 3.8 Changes in stress-strain relationship of one of the motion segments under cyclic compression test at cycles $1,10,50,100,500,1000$ and $5000 \ldots \ldots .49$

Figure 3.9 Frequency dependence of Strain (\%) of four specimens at cycles 100, 500 and 2000 .51

Figure 3.9 Frequency dependence of energy density at cycles 100,500 and $2000 \ldots 52$

Figure 4.1 Energy density comparison chart of 12 motion segments (3 from each spine) each tested for failure and cyclic compression 56 


\section{CHAPTER 1}

\section{INTRODUCTION}

\subsection{Overview}

Low back pain is experienced by most of the people at some time in their life (Papageorgiou et al., 1996). The area most commonly affected is the lower back, also known as the lumbar region. Injuries to the lumbar region can occur in two different ways: a sudden impact could cause an injury known as acute trauma and cumulative injuries are the other kind, where injuries are developed over a period of time.

Many back related injuries happen in industrial work environments. Lifting, reaching, twisting and, bending actions on a repetitive basis for long duration can accumulate damage in the spine leading to low back pain or an injury (Snook et al., 1978).

A safe working environment is necessary in every industry. When workers have a cumulative injury due to repetitive jobs such as bending and lifting his medical expenses becomes the responsibility of the employer. Hence cumulative injuries need to be considered when creating a safer work environment, and are the interest of this research. 


\subsection{Background}

Low back disorders are often triggered by jobs involving manual material handling activities. Risk factors for such activities have been classified into physical job demands, psychosocial and individual (NRC 2001). Most of the cumulative injuries occur during frequent lifting of moderate to heavy loads (Frymoyer et al., 1983) depending on the posture of the worker (Gallagher et al., 2002).

Many jobs involve frequent torso flexion, thus accumulating damage to the spine (Snook et al., 1988, Marras et al., 1993). Epidemiologic studies show repetitive lateral bending and lifting have major affect on the spine (Punnet et al., 1991), subjecting its tissues to stress. The lumbar region of the spine supports the weight of the torso while allowing a substantial range of motion, bearing the highest loads and tending to undergo the most motion (Panjabi et al., 1994) and is our area of interest.

Determining the mechanical properties of the thoracolumbar spine, and developing a measure of damage that is accumulated is a significant step in understanding the behavior of the spine under repetitive loads. In the following sections, the anatomy of the spine and previous research in this area is described.

\subsection{Literature Review}

The literature relating to the intervertebral disc of the thoracolumbar spine is described in this section. An overview of the anatomy of the spine is followed by each component of the spine, its physiological importance, physical properties, and the previous research relating to repetitive loading of the thoracolumbar spine. 


\subsubsection{Anatomy of Spine}

The spinal column is a mechanical structure in which the vertebrae articulate with each other in a controlled manner through a complex system of joints, ligaments, and levers. The rib cage in the human body stiffens this long, slender, ligamentous, bony structure (Sham et al., 2005).

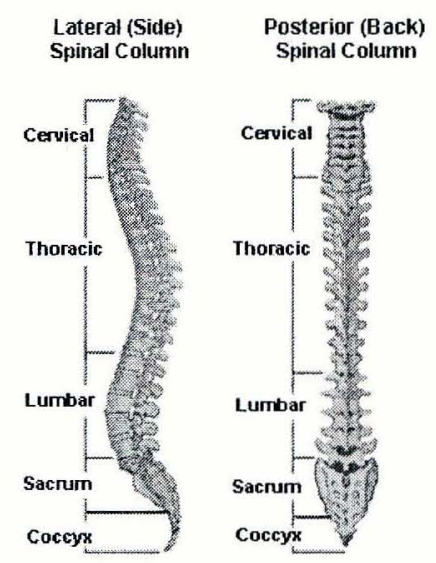

Figure 1.1 Lateral and posterior views of the spinal column (Adopted from Atlas of Human Anatomy by Frank Netter)

The spine has three fundamental bio-mechanical functions. Firstly, the weight of the head and trunk is transferred to the pelvis. Secondly, sufficient physiologic motion between the head, trunk and pelvis is achieved. Finally, it protects the delicate spinal cord from potentially damaging forces (Nordin et al., 1989).

The spine is made up of individual bones called vertebrae. These vertebrae are connected in the front of the spine by intervertebral discs that help support the spine and also allow it to move. Many ligaments and muscles are attached to the back of the spine provide the power for movement. The spine consists of seven cervical vertebrae, twelve thoracic vertebrae, five lumbar vertebrae, five sacral vertebrae, and three to four fused 
coccygeal segments (Bogduk, 1997). Parts of the spine which are of interest in this study are described below.

\subsubsection{Vertebrae}

The thoracolumbar vertebrae can be divided into three major components. The vertebral body (cylindrical element of the spinal column), posterior elements (consisting of laminae, the articular process, and the spinous processes), and pedicles (connect the posterior elements with the vertebral bodies).

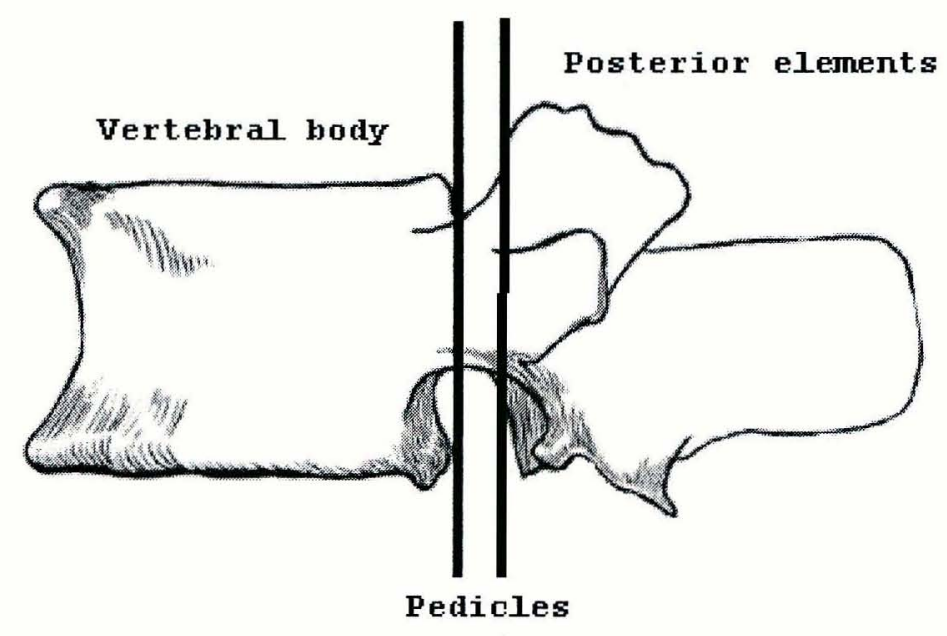

Figure 1.2 Division of vertebrae (adopted from Bogduk N, "Clinical Anatomy of the Lumbar Spine", 1997)

The vertebral body has cancellous bone in the center with a thin shell of cortical bone ideally designed to sustain compressive loads (White et al., 1990, Farfan et al., 1973). The compressive strength increases from the thoracic to lumbar levels (Carter et al., 1977). Each vertebra presents four articular processes. Extending upwards from the junction of the lamina and pedicle on each side is the superior articular process. The 
smooth area of the spine which in the intact spine is covered by articular cartilage called a facet. Projecting from the junction of the two laminae is a narrow blade of bone called the spinous process. Extending laterally from the junction of the pedicle and the lamina on each side is a flat rectangular bar of bone called transverse process. Together they constitute the posterior elements, which play a vital role in compressive strengths and in prevention of excessive deformation of the vertebrae (Adams et al., 1980).

\subsubsection{Vertebral Endplates}

A layer of cartilage between the vertebral body and the intervertebral disc is known as a vertebral endplate. One of the main purposes of the endplate is to pass the nuetrients by diffusion from the blood supply of the vertebral body to the avascular disc (Roberts et al., 19996). It is important in this study because most previous findings in post test examinations of compressive strengths indicated endplate fractures (Brinckmann et al., 1988, Yoganadan et al., 1994, Adams et al., 1993; 2000). Especially under cycling loading the age related calcification and degeneration of the endplates influence the compression characteristics (Brinckmann et al., 1983, Holmes et al., 1993).

\subsubsection{Intervertebral Disc}

The intervertebral disc constitutes 20 to $33 \%$ of the entire height of the vertebral column (Bogduk et al., 1976). It is the largest avascular structure, anchoring adjacent vertebral bodies, giving flexibility to the spine (Buckwalter et at., 1995). The disc consists of two basic components. The nucleus pulposus is the central region with a water content ranging from 70 to $90 \%$. The water content is highest at birth and tends to 
decrease with age (Grieve 1981). The nucleus pulposus is surrounded by annulus fibrosus, which gradually becomes differentiated from the periphery of the nucleus and forms the outer boundary of the disc (Bogduk 1997).

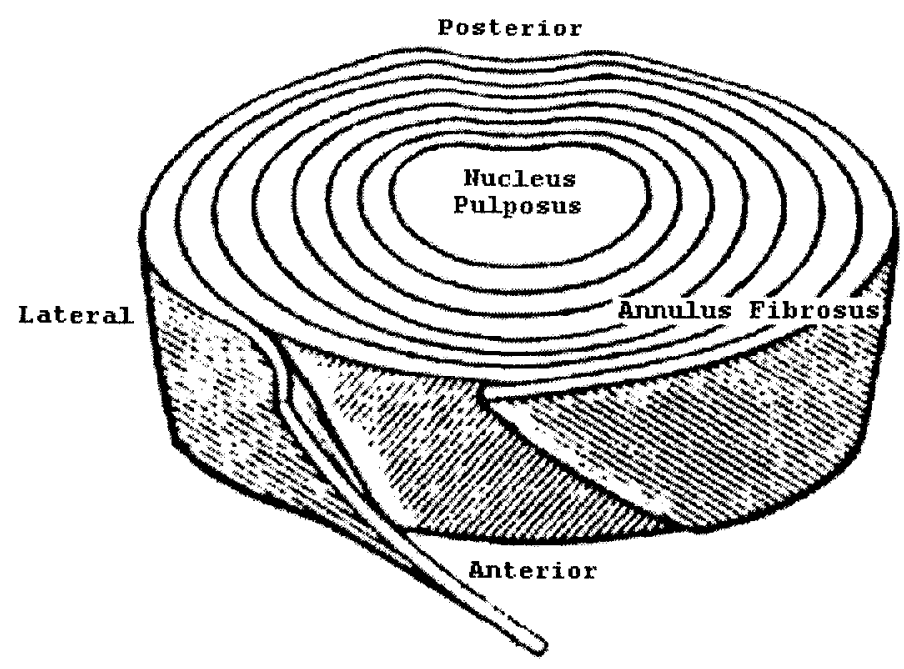

Figure 1.3 Concentric layers of annulus fibrosus and orientation of collagen fibers of intervertebral disc (adapted from White and Panjabi, "Clinical Biomechanics of the Spine", 1990)

The multiple layers of fibers in the annulus fibrosus are arranged in a helicoid manner (Figure 1.3). The directional orientations of the fibers allow the disc to exhibit viscoelastic properties (Kazarian et al., 1975).

\subsubsection{Prior Research}

The mechanical properties of the intervertebral discs during repetitive loading have been studied since the 1970 's. A literature review of prior research relating to the thoracolumbar spine is presented in this section. Testing of spine motion segments were 
performed either in in-vivo or in-vitro. Compressive strengths were generally tested in vitro, but with many limitations.

Spine tissue can be damaged not only from single impact load, but also by cyclic loading at lower load levels (Chaffin et al., 1973, Callaghan et al., 2001). K.G Davis et al., (1998) found that bending forces in the spine during lowering tasks were $56 \%$ greater than those during lifting tasks. Damage also depends on the posture of the spine during the task (Gallagher et al., 2002). Gallagher et al., (1999) studied coal miners as well as seven male subjects, ages ranging from 22 to 36 years and found that the changes in posture and cable load both influenced spinal loading. These tests were performed invivo.

Keller et al., (1987) tested fresh spine segments ranging from 37 to 82 years and found that intervertebral discs from older and degenerated spines creep more rapidly than younger and less degenerated spines. Schultz and colleagues (1979) performed similar research in the lumbar region under flexion, extension, bending, and torsion and found posterior elements had minor effects on the flexion of the segment, but was significant in extension and torsion. Kazarian et al., (1975) tested 32 spinal units of the thoracolumbar region for creep characteristics, at constant load and found that the rate of creep was dependent upon the condition of the nucleus pulposus. Panjabi et al., 1984 removed the nucleus and injured the annulus to study the mechanical behavior during disc injury and found that the changes in creep characteristics due to nucleus removal are greater than the changes due to annulus injury.

Endplate damage was studied by Adams et al., 2000 on cadaveric lumbar segments. They found that compressive stress leads to progressive deterioration of the 
matrix of the disc. Age of the segment is another important factor which has been studied by Buckwalter et al., 1995 and found human intervertebral discs undergo age related changes that decrease the spinal mobility and degeneration of facet joints. Cyclic loading for fatigue failure was studied by Brinckmann et al., 1988 and Keller et al., 1987 and considered number of cycles to failure as a damage measure.

\subsection{Limitations of Prior Research}

Although a limited amount of data on cyclic behavior of spinal segments is currently available, the tests are not completely documented and the loads, spine segment positioning, and cyclic frequency are not representative of those typically found during normal activities.

Frequencies typically found in industries during lifting tasks are in the range from 6 lifts per minute to 12 lifts per minute which is equal to a frequency of $0.1 \mathrm{~Hz}$ or $0.2 \mathrm{~Hz}$. Prior research has been done at frequencies ranging from $0.5 \mathrm{~Hz}$ to $25 \mathrm{~Hz}$, well beyond the normal conditions.

Table 1.1

Loading Frequencies and Failure criteria used in prior research

\begin{tabular}{|l|c|c|}
\hline \multicolumn{1}{|c|}{ Study } & Frequency & Failure Criteria \\
\hline Brown et al., 1957 & $18 \mathrm{~Hz}$ & Number of Cycles \\
\hline Hardy et al., 1958 & $2 \mathrm{~Hz}$ & Number of Cycles \\
\hline Hutton et al., 1983 & $0.67 \mathrm{~Hz}$ & Number of Cycles \\
\hline Liu et al., 1983 & $0.5 \mathrm{~Hz}$ & Number of Cycles \\
\hline Adams et al., 1983 & $25 \mathrm{~Hz}$ & Number of Cycles \\
\hline Hansson et al., 1987 & $2 \mathrm{~Hz}$ & Number of Cycles \\
\hline Keller et al., 1987 & $0.5 \mathrm{~Hz}$ & - \\
\hline Callaghan et al., 2000 & $1 \mathrm{~Hz}$ & Number of Cycles \\
\hline
\end{tabular}


Cycles to failure was considered to be a measure of damage which does not account for the load changes. Hence, 'cycles to failure' is not a suitable damage measure. Table 1.1 shows previous studies on cyclic and fatigue behavior are tabulated. Schulltz et al., (1979) studied mechanical properties of the Lumbar spine motion segments under a bending of $20.5 \mathrm{Nm}$. Panjabi et al., (1983) used a bending moment of $7.5 \mathrm{Nm}$ where as Ezquerro et al., (2004) used a bending moment of $6 \mathrm{Nm}$. When performing the compressive strengths Hutton et al., (1982) used $3000 \mathrm{~N} / \mathrm{sec}$, a large compression load. All studies used unrealistic spinal segment positioning, with frequencies not representative of what is typically found in normal activities.

\subsection{Discussion}

There is high probability of fatigue failure being a major cause of injury during repetitive tasks (Lotz et al., 2000). Prior research in this field is not completely documented. The spine segments tested were frozen for storage. The orientation of the segments was not similar to the normal orientation in the living human body. Cycling frequencies were very high compared to frequencies found in normal activities. The measure of damage was number of cycles which does not account for load changes. Hence there is a need for additional research to establish failure criteria and develop an understanding of the relationship between spinal loads and the development of fatigue failure in thoracolumbar motion segments oriented in neutral posture (posture of the spine in in-vivo while standing). 


\subsection{Proposal}

Testing was performed in accordance with a protocol approved by the Human Tissue Committee of the University of Louisville. Fresh human cadaveric spines were obtained from the Fresh Tissue Dissection Laboratory, University of Louisville.

Spine segments were oriented in a neutral posture and tested at frequencies of 0.1 and $0.2 \mathrm{~Hz}$. Creep and energy dissipation were considered as damage measures in this research. Creep has been used previously by Brinkmann et al., 1988, Keller et al., 1987, Adams et al., 1983. Energy dissipation is proposed as a damage measure in this research which had been a widely used damage measure in nonlinear mechanics. 


\section{CHAPTER 2}

\section{STUDY DESCRIPTION}

\subsection{Overview}

In order to find the mechanical properties of the spine in vitro, it is vital to perform testing under the conditions that simulate the human body during normal activities. Orientation of the spine and loading frequency in the previous work were not representative of those typically found during normal activities in the previous studies. Segment orientation was studied and the best fit for this study was selected.

\subsubsection{Significance of Orientation}

The spine is a multi-joint structure with non-linear geometry. It is ideally designed to protect the vertebral column against excessive compressive forces and strains that may be encountered during lifting and bending movements (Kuofi 1992). Hence the distribution of forces in the spine depends on the posture as shown by Aspden et al., (1989) and Jorgensen et al., (2003).

The lumbar region of the spine is the area which bears the highest loads and tends to undergo most motion (Panjabi et al., 1992). The area of interest in this research is aimed at studying the development of fatigue failure in the thoracolumbar region as well 
as to look at segmental orientation of the thoracolumbar region and its influence to failure during axial loads.

The curvature of the spine in the lumbar region is called Lordosis, and the curvature at the thoracic region is called Kyphosis. Both the thoracic curvature and lumbar curvature play a significant role in the distribution of forces in the spine (Bogduk et al., 1997). Hence, it is very important to correctly orient the spine during testing. The orientation of the vertebrae, intervertebral discs, and the endplates of human subjects have been studied in vivo and vitro. The next section gives a detailed description of the previous research in that area.

\subsubsection{Segment Orientation}

There have been several investigations on the orientation of the vertebral body using techniques like radiographic measurement (Pearcy et al., 1984, Sareste et al., 1985, Harrison et al, 2001), three dimensional x-ray analysis (Pearcy et al., 1984, Panjabi et al., 1992) and motion analysis (Lee et al., 2002). The radiographic measurements were considered to be the most reliable among these techniques (Sareste et al., 1985). Even though the angles of orientation of the thoracolumbar region have been studied by various researchers, the representation of angles was different for each study as described by the table 2.1 shown below: 
Table 2.1

Description of segment orientation in degrees with standard deviation in parenthesis from previous studies

\begin{tabular}{|c|c|c|c|c|c|c|c|c|c|c|c|c|c|c|c|c|c|}
\hline Study & T10T11 & $\mathrm{T} 11 / \mathrm{T} 12$ & $\mathrm{~T} 12 \pi 1$ & $\mathrm{~L} / \mathrm{L} 2$ & $\mathrm{~L} 2 / \mathrm{L} 3$ & $\mathrm{~L} 3 / \mathrm{LA}$ & LARS & LS/S1 & $\mathrm{T} 10$ & T11 & $\mathrm{T} 12$ & $\mathrm{Ll}$ & $\mathrm{L} 2$ & L3 & L4 & IS & \$1 \\
\hline Lysell et al., 1969 & $9(414)$ & $12(6-20)$ & $12(6-20)$ & $12(9-16)$ & $14(11-18)$ & $15(12-18)$ & $17(1421)$ & $20(18-22)$ & & & & $-10.6(6.2)$ & $-10.3(5.0)$ & -8.005 .9 & $2.0(7.0)$ & $16.9(7.5)$ & $36.76 .9)$ \\
\hline Portek et al., 1984 & & & & $2(5)$ & $7(4)$ & $11(3)$ & $17(5)$ & $38(6)$ & & & & & & & & & \\
\hline Pearcy etal., 1984 & & & & $13(3)$ & 14(2) & 13(2) & $16(4)$ & $14(5)$ & & & & & & & & & \\
\hline Gilad et al., (1986). & & & $14.24(8.5)$ & 13.2800 & $8.3(6.6)$ & $0.32(6.7)$ & $-11.65(6.8)$ & $-30.3(7.6)$ & & & $14.18(8.8)$ & $13.37(8.4)$ & $10.92(72)$ & $4.58(6)$. & $-5.12(6.8)$ & $-2096(.0)$ & $-35.19(7.9)$ \\
\hline Frobin et al., 1996 & & & 0.7 & 4.1 & 7.9 & 10.9 & 17.3 & 24.5 & & & & & & & & & \\
\hline $\begin{array}{l}\text { Chen (2000) } \\
\text { Videographic }\end{array}$ & & & & & & & & & & & & $-7.0(4.7)$ & 10 & $-6.3(5.4)$ & -3 & $2.7(2.9)$ & $6.3(4.2)$ \\
\hline $\begin{array}{c}\text { Chen (2000) } \\
\text { Radiographic }\end{array}$ & & & & & & & & & & & & $-9.7(6.2)$ & $-9.9(5.3)$ & $-4.9(5.9)$ & $2.8(7.5)$ & $17.8(6.8)$ & $37.5(6.8)$ \\
\hline Gohil et al., 2004 & & & & & & & & & $105(4.6)$ & $106(8.2)$ & $87(24.5)$ & $36(18.4)$ & $29(.21)$ & $29(10.33)$ & $35(11.12)$ & $44(13.39)$ & $55(14.8)$ \\
\hline
\end{tabular}


The variations in the angles for orientation occur because of the representation of the angles. For example Gilad et al., 1986 measured the segmental angles with respect to vertical where as Frobin et al., 1996 observed midplane angles.

In order to orient the spine in its neutral posture, the best suitable method for analysis of the radiographic measurements had to be determined. Centriod, Cobb, Trall and Harrison Posterior tangent methods were studied (Harrison et al., 2001) and the Harrison posterior tangent method was best suited for our testing.

\subsubsection{Segmental Posterior Tangent Method}

The superior posterior and inferior posterior vertebral body corners are used in the posterior tangent method. Posterior tangents were intersected to create relative rotational angles by Harrison et al., (1998). The angles created by the intersecting adjacent tangents are termed Harrison angles. The orientation angles, with mean and Standard deviation (SD), for the thoracolumbar region are given below:

Table 2.2

Harrison angles for the thoracolumbar region

\begin{tabular}{|l|c|c|}
\hline \multirow{2}{*}{ Level } & \multicolumn{2}{|c|}{ Referance Angles } \\
\cline { 2 - 3 } & Mean & SD \\
\hline T6/T & 6.3 & 4.1 \\
\hline T7/T8 & 5.7 & 3.4 \\
\hline T8/T9 & 3.8 & 3.6 \\
\hline T9/T10 & 2.4 & 3.7 \\
\hline T10/T11 & 3.4 & 3.8 \\
\hline T11/T12 & 3.2 & 4.1 \\
\hline T12L1 & -0.3 & 5.2 \\
\hline L1/L2 & -1 & 6.3 \\
\hline L2L3 & -6.8 & 4.4 \\
\hline L3/L4 & -10.9 & 4.5 \\
\hline L4L5 & -15.9 & 5.1 \\
\hline
\end{tabular}




\subsection{Study Design}

Testing of human spine segments was performed in accordance with a protocol approved by the Human Tissue Committee of the University of Louisville. Spine motion segments were dissected from each spine obtained from the human cadaver from the Fresh Tissue Dissection Laboratory, University of Louisville.

The spine was dissected into motion segments with one intervertebral disc and the adjacent vertebral bodies as shown in Figure 2.1.

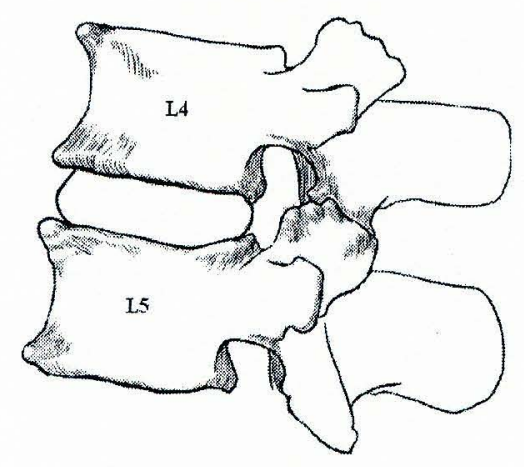

Figure 2.1 Schematic representation of motion segment

After dissection, initial CT-scans were performed to detect the presence of fracture in the vertebral bodies. Each segment was then randomly assigned to a testing group categorized by type of testing. Testing was performed in two series, the compression series and flexion series.

The compression series of testing consists of two tests: Ultimate axial compression failure test and cyclic axial compression test. The flexion series of testing consists of a ultimate bending test and a cyclic bending test. Detailed descriptions of these series are given in the following sections. 
All specimens were oriented per the reference angles shown in Table 2.2. A detailed block diagram of the experimental design is shown in Figure 2.2.

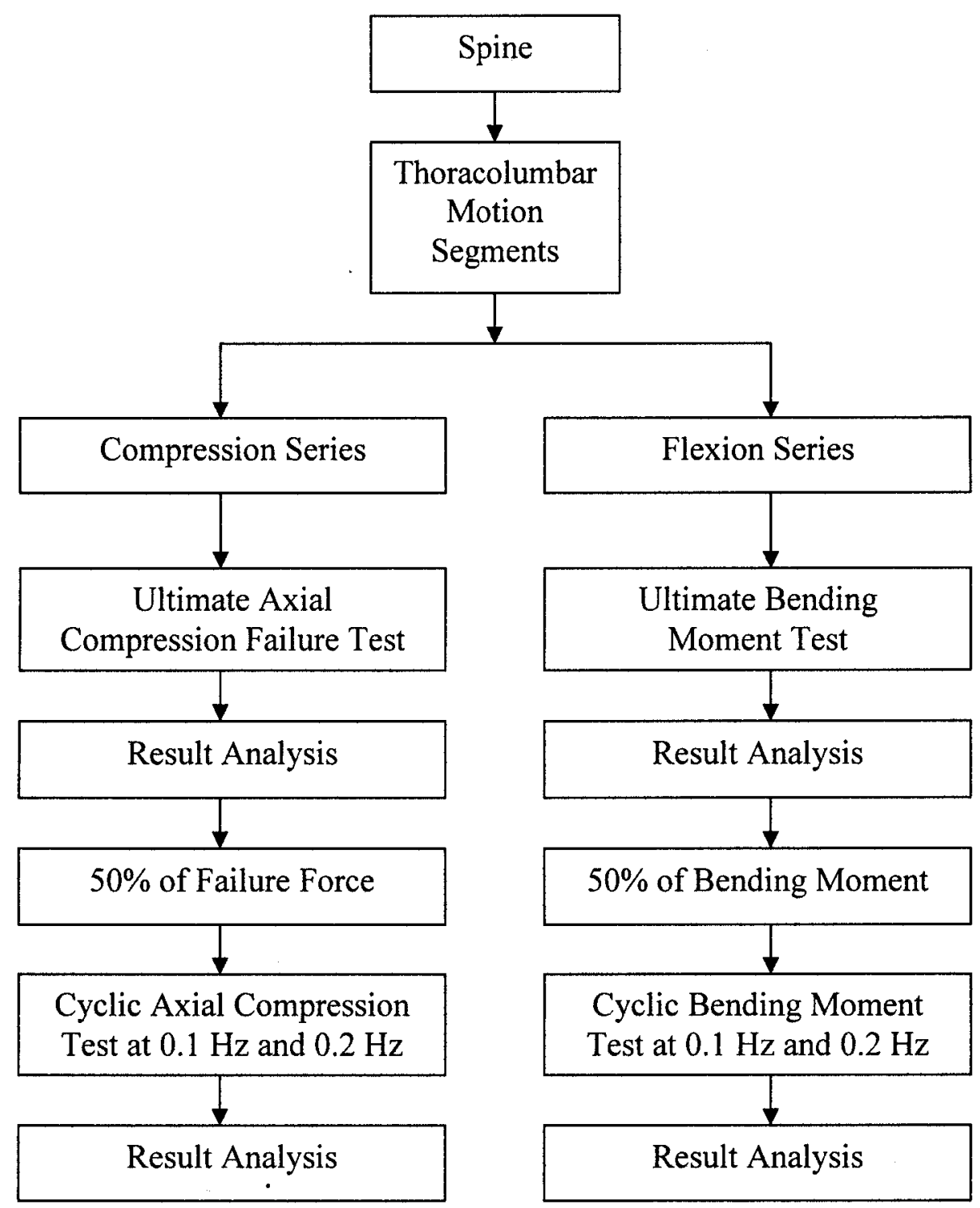

Figure 2.2 Schematic Block Diagram of the Experimental Design 
All motion segments were randomly assigned to a testing group. Table 2.3 shown below gives the four testing groups and categories.

Table 2.3

Test Series and Groups

\begin{tabular}{|c|c|}
\multicolumn{1}{|c|}{ Test } & Group \\
\cline { 1 - 1 } Compression Series & \\
\hline Ultimate Axial Compression Failure Test & A \\
\hline Cyclic Axial Compression Test at $0.1 \mathrm{~Hz}$ & $\mathbf{B}_{\mathbf{0 . 1}}$ \\
\hline Cyclic Axial Compression Test at $0.2 \mathrm{~Hz}$ & \\
\hline \multicolumn{1}{|c|}{ Flexion Series } & \\
\hline Ultimate Bending Test & C \\
\hline Cyclic Bending Test at $0.1 \mathrm{~Hz}$ & D \\
\hline
\end{tabular}

For all tests an axial compressive preload of $350 \mathrm{~N}$ was applied for $15 \mathrm{~min}$, simulating the torso load on the spine. Spine motion segments were constantly hydrated and body temperature maintained. A detailed description of each test, load type, and magnitude is given in the following section.

\subsubsection{Compression Series of Testing}

The compression series constituted two types of tests, axial compressive failure test and cyclic axial compression tests. An input of monotonic axial compressive load was applied quasi-statically at a displacement-controlled rate of $4 \mathrm{~mm} / \mathrm{hr}(0.0011$ $\mathrm{mm} / \mathrm{sec}$ ) in an ultimate compression test. The failure stress in newtons was determined by $100 \mathrm{~N}$ drop in axial force. 


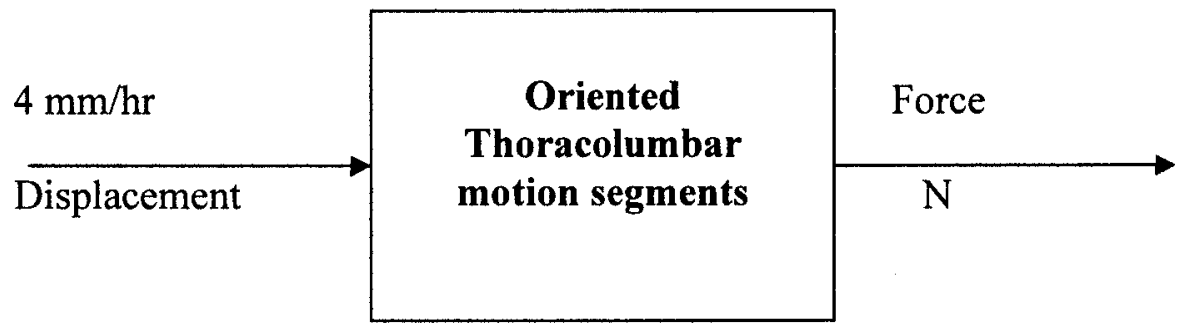

Figure 2.3 Schematic Diagram of Ultimate Compression Test

Cyclic axial compression tests were performed at $0.1 \mathrm{~Hz}(6$ lifts per minute) and $0.2 \mathrm{~Hz}$ (12 lifts per minute) in order to simulate typical work conditions. $50 \%$ of the failure stress from the ultimate compression test was applied at the respective frequencies for a period of 8 hours (homologous to typical work environment). Results were then analyzed. A input-output schematic diagram the cyclic compression test is shown in Figure 2.4.

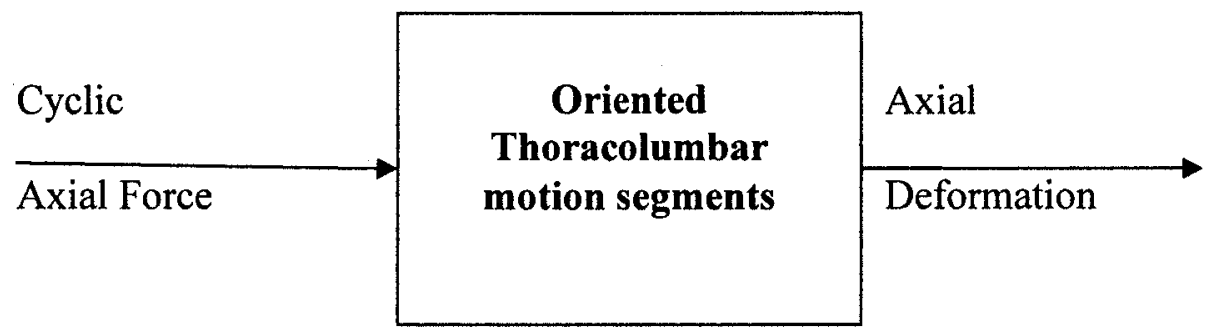

Figure 2.4 Schematic Diagram of Cyclic Axial Compression Test

\subsubsection{Flexion Series of Testing}

An ultimate bending test and cyclic bending tests constitute the flexion series of testing. In the ultimate bending test an eccentric compressive load was applied to produce 
an angular deformation at a rate of $0.2 \mathrm{Deg} / \mathrm{sec}$. Bending moment and angle of flexion were monitored. $50 \%$ of the maximum bending moment was applied at a constant rate of $0.2 \mathrm{~Hz}$ for a period of 8 hours. Moment, angles of flexion will be continuously monitored.

The entire experimental design for testing can be summarized into a tabular column with the load type, magnitude, and the cyclic frequency as shown in the table 2.4.

Table 2.4

Testing Parameters

\begin{tabular}{|l|c|c|c|}
\hline \multicolumn{1}{|c|}{ Load } & Load Magnitude & Frequency & Group \\
\hline $\begin{array}{l}\text { Axial } \\
\text { Compression }\end{array}$ & Ultimate Compression & - & A \\
\hline $\begin{array}{l}\text { Cyclic Axial } \\
\text { Compression }\end{array}$ & $\begin{array}{c}\mathbf{5 0 \%} \text { of Failure Force from } \\
\text { Group A }\end{array}$ & $\mathbf{0 . 1 / 0 . 2 ~ H z}$ & B \\
\hline $\begin{array}{l}\text { Bending } \\
\text { Moment }\end{array}$ & Ultimate Moment & - & C \\
\hline $\begin{array}{l}\text { Cyclic Bending } \\
\text { Moment }\end{array}$ & $\begin{array}{c}\mathbf{5 0 \%} \text { of Max. Moment from } \\
\text { Group C }\end{array}$ & $\mathbf{0 . 2 ~ H z}$ & D \\
\hline
\end{tabular}

\subsection{Material}

Seven human cadaveric spines were obtained from the Fresh Tissue Dissection Laboratory, University of Louisville. The spines were free from any spinal pathology. The spine was then separated into motion segments. Each motion segment would contain an intervertebral disc adjacent to two vertebral bodies. Depending on the length of the spines, motion segments were dissected into T6/T7, T7/T8, T8/T9, T9/T10, T10/T11, T12/L1, L1/L2, L2/L3, L3/L4, and L4/L5 motion segments.

The discs from the adjacent vertebral bodies of the motion segments were completely removed and care was taken not to damage the endplates of the vertebrae 
during dissection. Initial CT scans were performed to detect the presence of fractures which would affect the results of testing. Geometric properties of the vertebral bodies and the discs were tabulated which were used for normalization of the resultant data. The motion segments were then refrigerated for testing.

\subsection{Equipment}

In order to orient the motion segments and test for material properties as per the requirements discussed in section 2.2, an MTS (Material Testing System) and a special loading fixture were designed. The design and details of the equipment used for testing of spine motion segments are given in the following sections.

\subsubsection{Material Testing System (MTS)}

An MTS is a servo hydraulic testing machine. In order to meet the testing parameters shown in table 2.4, the MTS 858 Bionox Test system, MTS corp., Minneapolis, MN, USA was used. MTS 858 is a compact low force testing system with both static and dynamic loading capabilities. It provides axial loads up to $25 \mathrm{kN}$. The MTS consists of a loading unit, a digital controller, and system software support.

MTS has two channels of control, force and displacement. Two load cells, $5000 \mathrm{~N}$ and $25 \mathrm{kN}$ were used. The $25 \mathrm{kN}$ Load cell forms the base of the MTS unit and the 5000 $\mathrm{N}$ load cell is used in the flexion series of testing mounted to the base of the MTS actuator. Data can be monitored at the display unit. 


\subsubsection{Loading Fixture}

Spine motion segments oriented at the neutral angle and rigidly fixed during testing. In order to properly measure the material properties, a fixture is necessary for testing which would not only withstand forces during testing but also fit the MTS. A special fixture was designed for this research. The fixture consists of three basic parts, pots, potangulars and the adapter plates. A schematic diagram of the loading fixture and its parts are show below:

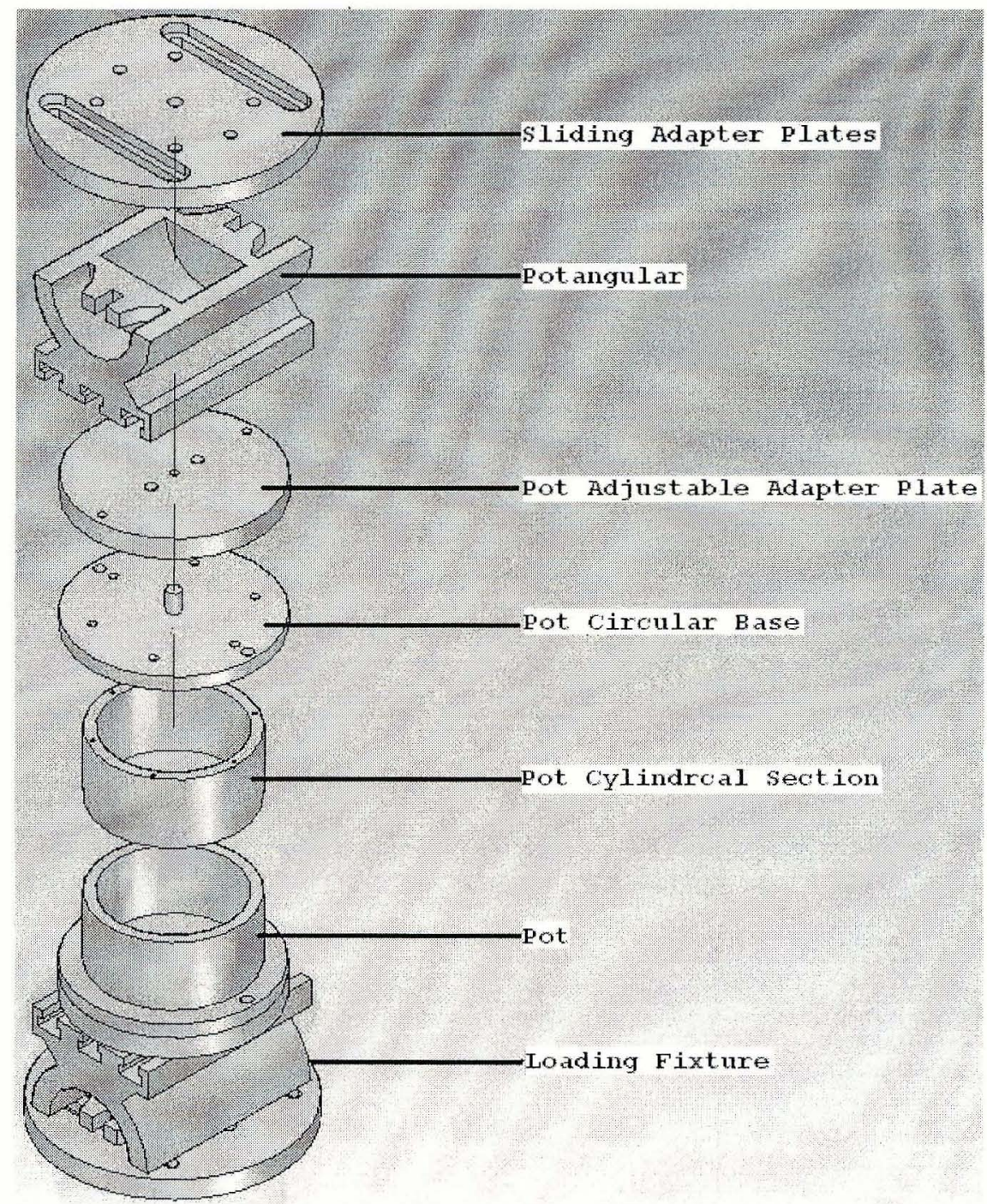

Figure 2.5 Schematic Diagram of the Loading Fixture and its detachable sections 
Spine motion segments vary in size depending on the level being tested and also by the gender, and age of the person (Jackson et al., 1994). This variation of the motion segments has led to the design of a fixture which would fit motion segments of any size. Three main parameters important for designing the pot were the posterior height, anterior height and the width of the vertebral disc. Research was done to find these parameters in previous studies and the values are tabulated in table 2.5.

Table 2.5

Description of Anterior and Posterior heights of the vertebrae and disc width with standard deviation in parenthesis

\begin{tabular}{|c|c|c|c|c|c|}
\hline \multirow{4}{*}{ Study } & Level & $\begin{array}{c}\text { Anterior } \\
\text { Height }(\mathbf{m m})\end{array}$ & $\begin{array}{c}\text { Posterior } \\
\text { Height(mm) }\end{array}$ & $\begin{array}{c}\text { Disc } \\
\text { Level }\end{array}$ & $\begin{array}{c}\text { Disc Width } \\
\text { (mm) }\end{array}$ \\
\hline \multirow{4}{*}{$\begin{array}{c}\text { Gilad et al., } \\
1986\end{array}$} & L1 & $25.4(2.2)$ & $27.1(2.1)$ & L1/L2 & 34.1 \\
\cline { 2 - 6 } & L2 & $27.2(2.0)$ & $28.0(2.1)$ & L2/L3 & 34.7 \\
\cline { 2 - 6 } & L3 & $27.9(2.1)$ & $27.9(2.1)$ & L3/L4 & 34.6 \\
\cline { 2 - 6 } & L4 & $27.4(2.2)$ & $27.1(2.3)$ & L4/L5 & 34.9 \\
\cline { 2 - 6 } & L5 & $28.3(2.1)$ & $25.7(2.5)$ & & 33.9 \\
\hline \multirow{4}{*}{$\begin{array}{c}\text { Berry et al., } \\
1987\end{array}$} & L1 & $25.0(2.9)$ & $25.8(2.1)$ & L1/L2 & 31.9 \\
\cline { 2 - 6 } & L2 & $27.9(1.9)$ & $25.2(2.2)$ & L2/L3 & 33.3 \\
\cline { 2 - 6 } & L3 & $27.4(1.7)$ & $26.0(1.6)$ & L3/L4 & 33.9 \\
\cline { 2 - 6 } & L4 & $26.7(1.5)$ & $26.4(1.7)$ & L4/L5 & 34.9 \\
\cline { 2 - 6 } & L5 & $28.7(1.9)$ & $23.1(1.5)$ & & 35.1 \\
\hline \multirow{3}{*}{$\begin{array}{c}\text { Panjabhi et al., } \\
1992\end{array}$} & L1 & - & $23.8(1.0)$ & L1/L2 & 34 \\
\cline { 2 - 6 } & L2 & - & $24.3(1.0)$ & L2/L3 & 34 \\
\cline { 2 - 6 } & L3 & - & $23.8(1.1)$ & L3/L4 & 33 \\
\cline { 2 - 6 } 1992 & L4 & - & $24.1(1.1)$ & L4/L5 & 33 \\
\cline { 2 - 6 } & L5 & - & $22.9(1.0)$ & & 31 \\
\hline
\end{tabular}

The height of the cylindrical section of the pot was manufactured to be $51 \mathrm{~mm}$ to fit vertebrae of any height. Since the average width of the disc from previous studies was 
$34 \mathrm{~mm}$, the diameter of the cylindrical section was $152.4 \mathrm{~mm}$. Pots were manufactured with 6061 aluminum.

An epoxy resin commercially known as Bondo (Dynatron Corporation, Atlanta, GA) was used to pot the motion segment. Body filler is mixed with hardener to form a semi solid gel inside the pot. The motion segment which is ready for testing is potted. The semi solid gel hardens in 3-4 minutes fixing the motion segment rigidly inside the pot. Screw holes are provided to drive the screws into the epoxy in order to hold the epoxy resin inside the pot. Adjustable slots are provided to adjust the pot inside the fixture.

At the end of each test the motion segment is removed by removing the screws that hold the Bondo. The pots were then cleaned and prepared for the next test.

\subsubsection{Potangulars}

Angular device attached to the base of the pots in the loading fixture (Figure 2.5). They orient the pots at the desired angle and were hence named Potangulars. Orientating the spinal segments (discussed in section 2.1.1) at Harrison angles (Table 2.2) required a special design. The potangular resembles a cylinder with a moving plate perpendicular to its axis.

Sliding slots are provided in the cylinder for the top section to slide freely on the circumference of the cylinder. The pot is angularly shifted and hence the motion segment is oriented. The sliding section is clamped at the required angle. In order to achieve the angles in table 2.2, potangulars have been designed to be adjustable to a maximum angle of 40 degrees. 
Each potangular has two adjacent adapter plates. The plate on the sliding section attaches to the base of the pot, allowing the adjustability of the pots. A second adapter plate forms the base of the potangular which mounts on the $25 \mathrm{kN}$ load cell of the MTS. Sliding slots are provided for these adapter plates to negate the shift in the axial center resulting from the pot orientation. The pots can thus be positioned in exact axial center of the MTS using the sliding slots of the adapter plates shown in Figure 2.6.

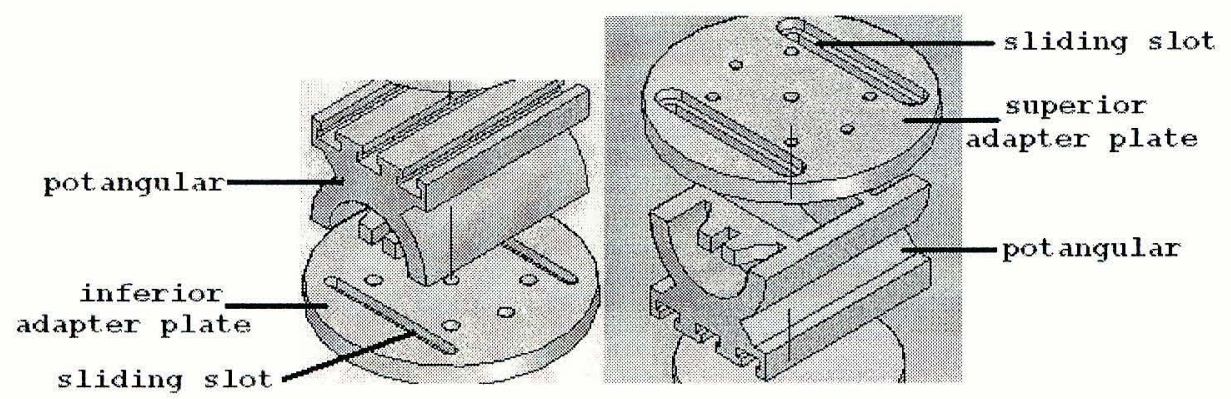

Figure 2.6 Schematic diagram of the adapter plates of potangular

Orienting the pots with the potangulars to achieve the exact neutral angles (Table 2.2) required precision. The resultant angles were negative in the lumbar region and positive in the thoracic region. Hence to maintain a standard, quadrant system was used in calculating the resultant angle. The right quadrant of the superior potangular is positive and the left quadrant considered negative. Inferior potangulars left quadrant is positive and right quadrant negative. The resultant angles derived using this quadrant system resemble Harrison angles (Table 2.2). 


\subsubsection{Moment Arm}

MTS is limited to axial load. Therefore in order to apply bending moment, the loading fixture was needed to be slightly modified. Moment arm was designed based on the principle of load being applied at an offset to the axial center shown in Figure 2.7.

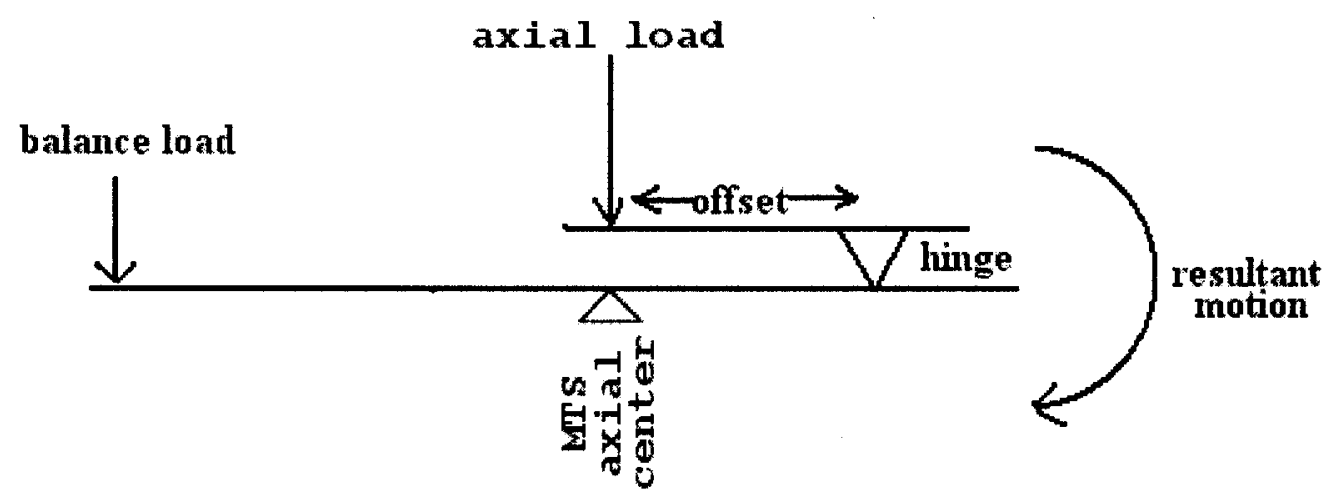

Figure 2.7 Schematic representation of Moment Arm (Adopted from Intervertebral measurement of lumbar segmental motion with a new measuring device Y.M. Zhang et al., 1998)

When load is applied at an offset to the axial center of the MTS, initial conditions can be controlled using a balance load. Moment applied on the motion segment can be derived by the formula

$$
\mathrm{M}=\mathrm{F}^{*} \mathrm{~d}
$$

Where moment $(\mathrm{Nm})$ is represented by $\mathrm{M}$, force $(\mathrm{N})$ by $\mathrm{F}$ and distance $(\mathrm{m})$ by $\mathrm{d}$. The distance between the MTS axial center and the hinge is known. The force exerted in the fixture is monitored by the $5000 \mathrm{~N}$ load cell mounted on the MTS actuator. Angular deformation can be controlled and monitored by the potentiometer. The mechanical hinge is coupled by a $22 \mathrm{~mm}$ precision wirewound potentiometer with linearity of $\pm 0.25 \%$. 
Weights on the other end of the connecting rod provide balance and control to the arrangement.

\subsection{Testing}

Testing was performed in compression series and flexion series as discussed in section 2.2. Care was taken to simulate the work environment experienced by humans in vivo. Test conditions, procedure and data collection are described in brief.

Body temperatures of normal humans range from 36-38 degrees centigrade with a humidity 70 to $80 \%$. In order to simulate the same conditions during testing in vitro, the room temperature (where the testing was performed) was maintained close to the body temperature. To prevent the specimen from drying out, saline water was sprayed on the motion segment every 10 minutes during the test.

\subsubsection{Preload}

The thoracolumbar region of the spine is constantly under compressive load due to upper body weight. The upper body constitutes the torso and the head which is typically represented by one half of the body weight ie., $350 \mathrm{~N}$. To simulate the conditions in-vivo, motion segment are preloaded with a compressive force of $350 \mathrm{~N}$.

In compression series, MTS is programmed to exert a $350 \mathrm{~N}$ compressive force. In flexion series, the weight of the moment arm arrangement with the potangular fixture and balance weights are adjusted to be $350 \mathrm{~N}$. In both the testing series, the motion segments are under static load for a period of $15 \mathrm{~min}$. 


\subsubsection{Test Procedure}

A step by step procedure for testing the spinal motion segments is presented in this section.

\subsubsection{Compression Series}

Initial setup for compression tests:

1. The motion segment is carefully cleaned and size measurements taken.

2. The superior vertebra of the motion segment is carefully potted, so that one half of the vertebrae is rigidly fixed into the Bondo.

3. The potangulars are set to resultant angle (Table 2.2).

4. The pot containing the potted segment is oriented using the Potangular arrangement and lowered into the inferior pot using the MTS actuator.

5. The set up is left for the setting ( $3 \mathrm{~min})$ until the Bondo hardens.

6. The MTS machine is reset (to establish a starting position).

7. A quasi-static load of $350 \mathrm{~N}$ is preloaded on the test segment to simulate torso weight.

Axial Compression Failure Test:

1. Axial compressive load was exerted on the segment through a displacement control mechanism at a rate of $0.0012 \mathrm{~mm} / \mathrm{sec}$.

2. Resultant force on the $\operatorname{disc}(\mathrm{N})$ and axial deformation ( $\mathrm{mm}$ ) are constantly recorded.

3. Test was stopped once the failure criterion (section 2.2.1) is reached. 
Cyclic Compression Test:

1. A Cyclic axial compressive load, $50 \%$ of the failure stress was applied by a Force-controlled mechanism at frequencies 0.1 and $0.2 \mathrm{~Hz}$.

2. Resultant axial deformation of the disc (mm), force exerted on the segment $(\mathrm{N})$ were monitored constantly.

3. Test was stopped at the end of 8 hour period.

\subsubsection{Flexion Series}

Initial setup for flexion tests:

1. The motion segment is carefully cleaned and size measurements taken.

2. The MTS Actuator is setup with the moment arm arrangement.

3. The superior vertebra of the motion segment is carefully potted, so that one half of the vertebrae is rigidly fixed into the Bondo.

4. The potangulars are set to resultant angle (Table 2.2).

5. The pot containing the potted segment is oriented using the Potangular arrangement and lowered into the inferior pot using the MTS actuator.

6. The set up is left for the setting ( $3 \mathrm{~min})$ until the Bondo hardens.

7. The MTS machine is reset (to establish a starting position).

8. A quasi-static load of $350 \mathrm{~N}$ is preloaded on the test segment to simulate torso weight. 
Ultimate Flexion Test:

1. Angular displacement at a rate of $0.2 \mathrm{deg} / \mathrm{sec}$ was applied on the test segment through the moment arm arrangement.

2. Angular deformation (deg) and, resultant bending moment (Nm) were constantly measured.

3. The test was stopped when maximum angular displacement of the machine was achieved.

Cyclic Flexion Test:

1. Cyclic Bending, $50 \%$ of the maximum bending moment was applied by a force controlled mechanism at frequency of $0.2 \mathrm{~Hz}$.

2. Bending moment $(\mathrm{Nm})$ and resultant angular deformation (deg) were constantly measured.

3. Test was stopped at the end of 8 hour period. 


\subsection{Summary}

This study was designed to determine the mechanical properties of the spine motion segments. Two series of testing were proposed and implemented. The compression series of testing consisted of an ultimate compression failure test, from which $50 \%$ of the failure load was taken as input to a series of cyclic axial compression tests. The flexion series of testing had a bending moment failure test, from which $50 \%$ of the maximum bending moment, was taken as the applied load for second moment tests.

All cyclic tests were tested for a period of 8 hours homologous to typical work environment at a frequency of either $0.1 \mathrm{~Hz}$ ( 6 lifts per minute) or $0.2 \mathrm{~Hz}$ (12 lifts per minute). A special loading fixture was designed to orient and test the motion segments. A few compressive failure tests were done with straight vertical orientation to study the effects of orientation of motion segments. All other tests were performed with the neutral angle orientation of the motion segments. Force $(\mathrm{N})$, Moment $(\mathrm{Nm})$, axial creep $(\mathrm{mm})$, angular deformation (deg) and number of cycles were continuously measured during testing for further analysis. 


\section{CHAPTER 3}

\section{RESULTS AND ANALYSIS}

The results of testing spinal motion segments are presented in four parts: ultimate compression test results; cyclic compression test results; ultimate bending test results; and cyclic bending test results. All test data were collected at a sampling rate of $20 \mathrm{~Hz}$ during the test and the MTS generated files were converted into Excel (Microsoft) sheets for analysis. Measurements of the motion segments were also taken before each test in order to allow for normalization of the results. The discussion of the results begins with definitions of the terminology associated with the study.

\subsection{Definitions}

\section{Creep}

Creep is defined as the tendency of a material to deform under sustained or cyclic loads. In this study, the deformation of the intervertebral disc due to cyclic application of compressive stress (50\% of ultimate failure stress) during the 8 hour period of testing is referred to as creep. This is appropriate as it refers to the accumulation of deformation over time. 


\section{Axial Deformation}

Axial deformation is the change in height of the disc under loading. It is measured at the centroid of the disc.

\section{Angular Deformation}

Angular deformation is the change in relative orientation between the top and bottom of the disc. It is a measure of the rotation occurring within and across the disc.

\section{Failure Stress}

The force per unit area at which the failure criterion is reached in the intervertebral disc during the ultimate compression failure test.

\section{Energy Density}

The amount of strain energy dissipated in the intervertebral disc per unit volume.

\subsection{Ultimate Compression Failure Test Results}

Nine motion segments were tested in this study, three without orientation (axially aligned) and six oriented at the neutral angle as defined by the range of Harrison angles shown in Table 2.2. Only thoracic motion segments were tested for failure since the posterior elements would influence the failure force in the lumbar region. The orientation chart for all motion segments tested to compression failure is shown in Table 3.1. 
Table 3.1

Description of age, gender and resultant orientation angles of the potangulars in degrees for the specimens tested for compression failure.

\begin{tabular}{|c|c|c|c|c|c|c|}
\hline \multirow{2}{*}{ Specimen } & \multirow{2}{*}{ Gender } & \multirow{2}{*}{ Age } & \multicolumn{4}{|c|}{ Oriented angle per level tested } \\
\cline { 4 - 7 } & & & T6/T7 & T7/T8 & T8/T9 & T9/T10 \\
\hline 737 & $\mathrm{M}$ & 75 & - & - & 3 & - \\
\hline 738 & $\mathrm{M}$ & 66 & - & - & 2 & - \\
\hline 739 & $\mathrm{M}$ & 67 & - & - & 3 & - \\
\hline 740 & $\mathrm{~F}$ & 87 & - & - & 1 & - \\
\hline 741 & $\mathrm{~F}$ & 98 & 0 & - & 1 & - \\
\hline 1914 & $\mathrm{~F}$ & 91 & - & 1 & - & 0 \\
\hline 1915 & $\mathrm{M}$ & 71 & - & 4 & - & 0 \\
\hline
\end{tabular}

The blank portions in table 3.1 indicate no axial compression failure test was performed on that motion segment. Only one motion segment from each spine was tested for compression failure with orientation, to provide the input load for the cyclic tests. A resultant angle value of zero represents the level being tested without orientation.

The compression force exerted by the MTS actuator and the axial deformation of the intervertebral disc were constantly monitored and measured. An example of the output from an ultimate compression failure test, with force in newtons plotted versus disc deformation (mm) is shown in Figure 3.1. Preload represents the initial force of 350 $\mathrm{N}$ is applied to the motions segment. The flat potion of the behavior pattern is the $15 \mathrm{~min}$ hold of $350 \mathrm{~N}$ preload. The increase of compressive force at standard rate in the next portion of the graph was due to the displacement control mechanism at a rate of $4 \mathrm{~mm} / \mathrm{hr}$. A sudden drop of force is observed at failure. The disc deformation $(\mathrm{mm})$ and failure force $(\mathrm{N})$ are noted for further analysis. 
Figure 3.1 Behavior of Force $(\mathrm{N})$ and disc deformation $(\mathrm{mm})$ of one of the motion segments tested for ultimate compression.

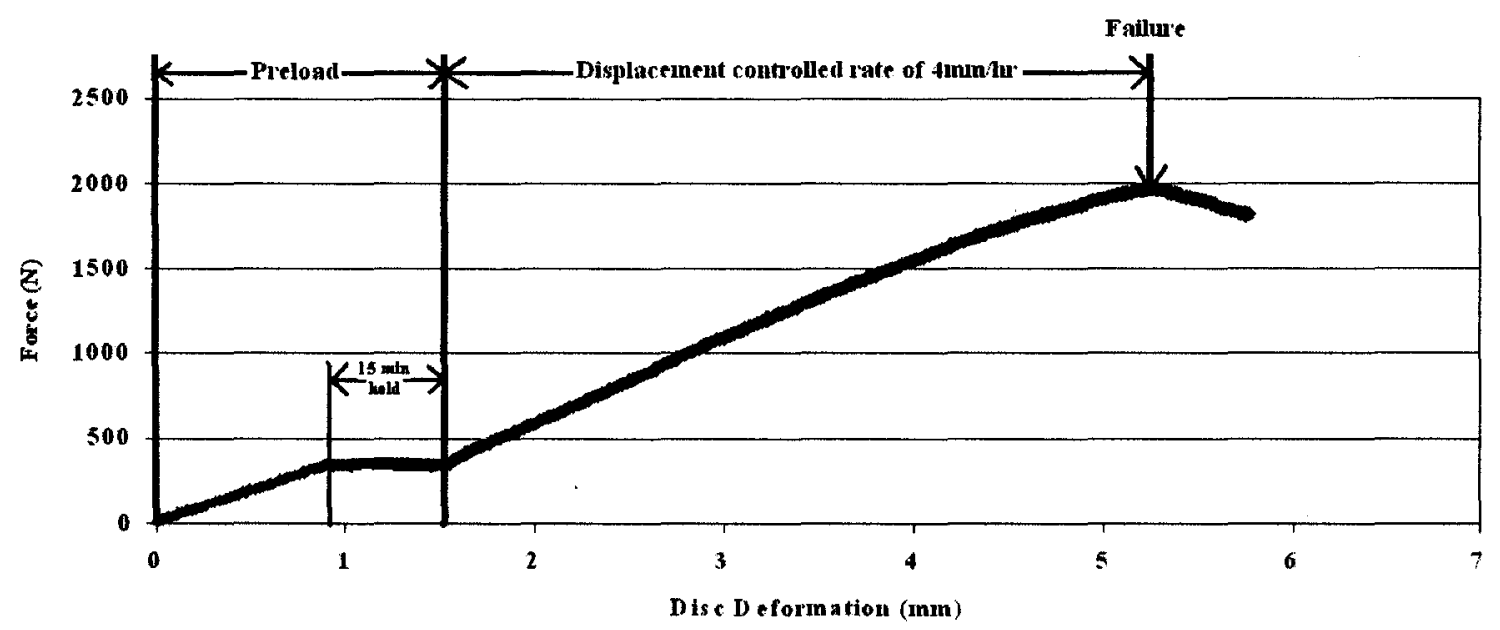

The slope of the graph is the stiffness of the intervertebral disc. The sudden negative change in force indicates failure of the disc. The failure force $(\mathrm{N})$ and the disc deformation $(\mathrm{mm})$ at failure are noted for further analysis. From measurements of the motion segment taken before the test the average disc height $(\mathrm{mm})$ and volume of the disc $\left(\mathrm{mm}^{3}\right)$ are calculated. The axial deformation of the disc is calculated as a percentage of the initial average disc height. The amount of energy dissipated by the intervertebral disc is calculated using the formula

$$
\mathrm{E}=0.5^{*}\left(\mathrm{~F}_{2}+\mathrm{F}_{1}\right) *\left(\mathrm{~A}_{2}-\mathrm{A}_{1}\right)+\mathrm{E}_{\text {initial }}
$$

where energy dissipated $E(\mathrm{KJ})$ is the sum of axial forces $F_{1}$ and $F_{2}(N)$ at the beginning and end of the load step and $A_{1}$ and $A_{2}(\mathrm{~mm})$ are the corresponding axial deformations.

Most of the ultimate compression failure tests showed a significant force drop at failure. An average disc deformation of $1.58 \mathrm{~mm}$ was observed during preload. Thoracic 
spine motion segments oriented at the neutral angle attained and average failure force of $2800 \mathrm{~N}$ with an average ED of $0.72 \mathrm{KJ} / \mathrm{mm}^{3}$ with a standard deviation of $0.32 \mathrm{KJ} / \mathrm{mm}^{3}$.

The results indicated a increase in failure force for motion segments without orientation compared to those segments oriented in the neutral position as shown in Figure 3.3. An average failure force of $1713 \mathrm{~N}$ was observed with energy density values of $0.56(0.28) \mathrm{KJ} / \mathrm{mm}^{3}$ in tests without orientation compared to an average failure force of $1488 \mathrm{~N}$ with energy density values of $0.8(0.4) \mathrm{KJ} / \mathrm{mm}^{3}$ in tests with orientation. The energy densities of the motion segments demonstrate an inverse behavior from the force values, where $\mathrm{ED}$ of the motion segments with orientation was greater than the $\mathrm{ED}$ of motion segments without orientation.

In order to normalize the data, the energy density (ED) of the disc was calculated by dividing the dissipated energy by the volume of the disc. Energy density of the intervertebral disc was calculated in terms of $\mathrm{KJ} / \mathrm{mm}^{3}$. All values are tabulated with respect to the specimen number and the level being tested. The specimen number indicates the cadaver from which the specimen was obtained, including the gender of the cadaver. A summary of the ultimate compression failure test results is shown in Table 3.2 . 
Table 3.2

Summary of test results of all ultimate compression failure tests tabulated with respect to the specimen number and level.

\begin{tabular}{|c|c|c|c|c|c|c|c|c|c|}
\hline \multicolumn{10}{|c|}{ ULTIMATE COMPRESSIVE TESTS } \\
\hline Specimen \# & M 737 & M 738 & F740 & F741 & F741 & M1915 & M1915 & F1914 & F1914 \\
\hline Level & T8/T9 & T8/T9 & T8/T9 & T8/T9 & T6/T7 & $\mathrm{T7/T8}$ & T9/T10 & $\mathrm{T} 7 / \mathrm{T} 8$ & T9/T10 \\
\hline Failure Force $(\mathbf{N})$ & 3332.97 & 2295.39 & 1961.36 & 1216.65 & 1322.26 & 2205.93 & 2426.58 & 1041.6 & 1319.38 \\
\hline Actuator Displacement at Fail & 5.40369 & 4.41649 & 5.22563 & 3.89438 & 3.83954 & 4.81141 & 4.9153 & 4.01294 & 4.34448 \\
\hline Energy at Failure (KJ) & 8613.7 & 3969.31 & 4563.59 & 1889.66 & 1794.46 & 4176.01 & 4669.14 & 2088.15 & 2506.27 \\
\hline Energy Density At Failure $\left(K J / \mathrm{mm}^{\wedge} 3\right)$ & 0.71455 & 0.65026 & 1.76966 & 0.55478 & 0.98304 & 1.08663 & 0.76656 & 0.51839 & 0.35961 \\
\hline Area of the Disc $\left(\operatorname{mm}^{\wedge} 2\right)$ & 1610.58 & 1150.55 & 660.786 & 951.987 & 795.379 & 1080.01 & 1220.23 & 927.082 & 1134.07 \\
\hline Volume of the Disc(mm 3$)$ & 12054.8 & 6104.15 & 2578.8 & 3406.17 & 1825.43 & 3843.09 & 6091.05 & 4028.15 & 6969.42 \\
\hline Oreintation & Neutral & Neutral & Neutral & Neutral & w/o Orient & Neutral & w/o Orient & Neutral & wio Orient \\
\hline Average Disc Height(mm) & 8.96667 & 6.76667 & 5.45 & 5.16667 & 4.025 & 5.13333 & 6.56667 & 5.71667 & 8.01667 \\
\hline Disc Height After Preload(mm) & 7.484743 & 5.30542 & 3.90262 & 3.57795 & 2.29504 & 3.55839 & 4.99173 & 4.34498 & 6.14547 \\
\hline Failure Criteria & $\begin{array}{c}75 \% \text { Disc } \\
\text { Def } \\
\end{array}$ & $\begin{array}{l}\text { Force } \\
\text { Drop }\end{array}$ & $\begin{array}{l}\text { Force } \\
\text { Drop }\end{array}$ & $\begin{array}{l}\text { Force } \\
\text { Drop }\end{array}$ & $\begin{array}{l}\text { Force } \\
\text { Drop }\end{array}$ & $\begin{array}{l}\text { Force } \\
\text { Drop }\end{array}$ & $\begin{array}{l}\text { Force } \\
\text { Drop }\end{array}$ & $\begin{array}{l}\text { Force } \\
\text { Drop }\end{array}$ & $\begin{array}{l}\text { Force } \\
\text { Drop }\end{array}$ \\
\hline Disc Height at Failure & 3.56298 & 2.35018 & 0.22437 & 1.27229 & 0.18546 & 0.32192 & 1.65137 & 1.70373 & 3.67219 \\
\hline$\%$ Deformation & -52.397 & -55.702 & -94.251 & -64.441 & -91.919 & -90.953 & -66.918 & -60.789 & -40.246 \\
\hline
\end{tabular}




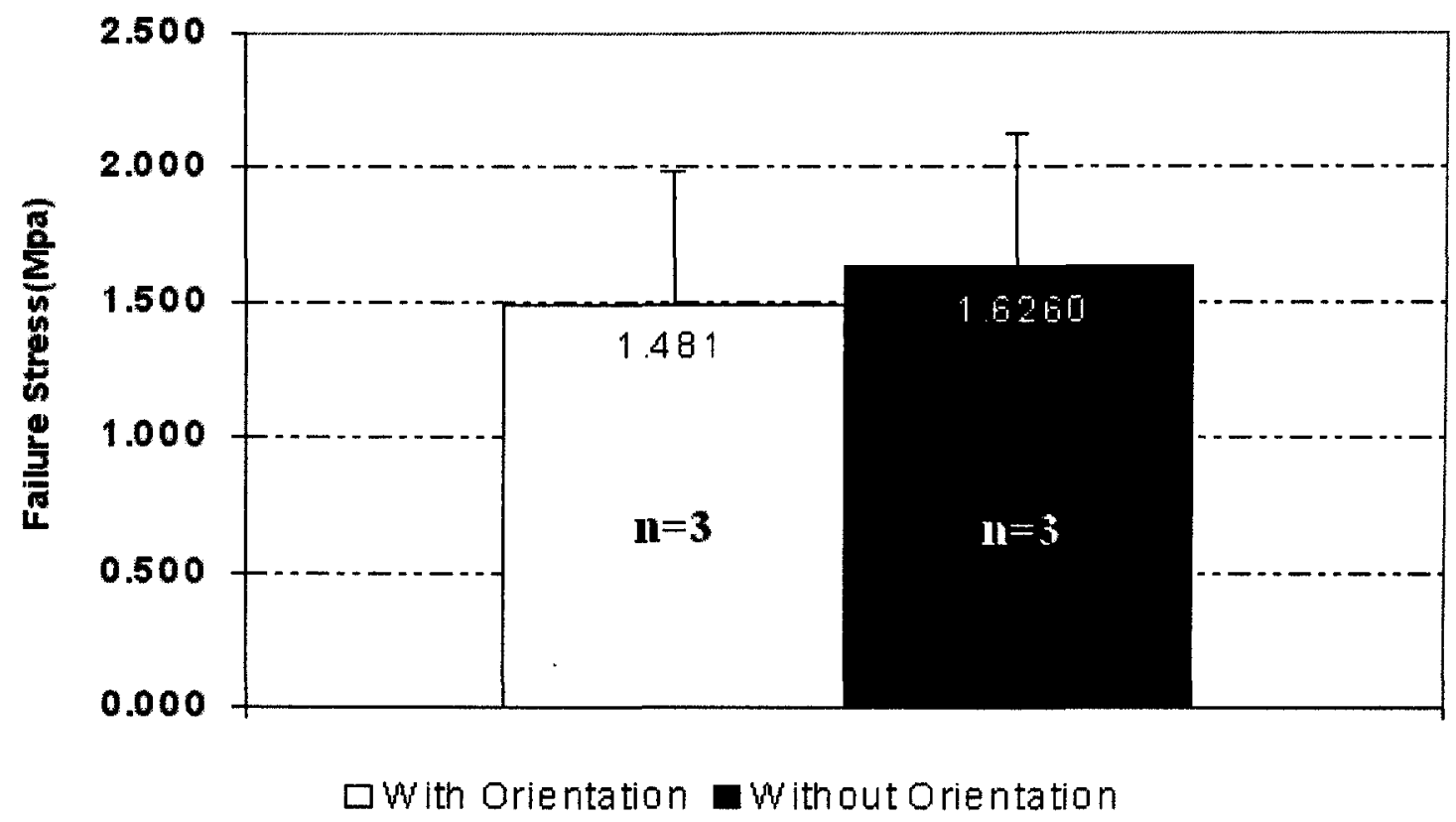

Figure 3.2 Comparison of the effect of segment orientation on failure stress for the 6 specimens, 2 from each spine tested with and without orientations.

The failure stress (MPa) of each motion segment was calculated. Figure 3.2 shows the comparison chart between the average failure stresses of 6 motion segments ( 2 motion segments from each spine) tested with and without orientation. An increase of average failure stress was observed in segments tested without orientation. The difference between failure stresses indicates the effect of segment orientation in testing.

\subsection{Cyclic Axial Compression Test Results}

Eight motion segments were tested in cyclic axial compression, four at a frequency of $0.1 \mathrm{~Hz}$, which represents 6 lifts per minute, and the remaining four at $0.2 \mathrm{~Hz}$ (12 lifts per minute). 


\subsubsection{Cyclic Axial Compression Test results at $0.1 \mathrm{~Hz}$}

Four thoracolumbar motion segments were tested, all oriented at their neutral angle (Table 2.2). The motion segments were loaded at a frequency of $0.1 \mathrm{~Hz}$ with a load equal to one-half of the failure force measured from the axial compression failure test on a motion segment from the same spine. Testing was performed for a period of 8 hours (approximately 2600 cycles). The cyclic compression force and axial deformation of the intervertebral disc were constantly monitored.

Using the geometric measurements of the motion segment taken before the test, the average disc height $(\mathrm{mm})$ and volume of the disc $\left(\mathrm{mm}^{3}\right)$ were calculated. Axial deformation as a percentage of the initial disc height was calculated. The average values of axial deformation of the disc (\%) were calculated.

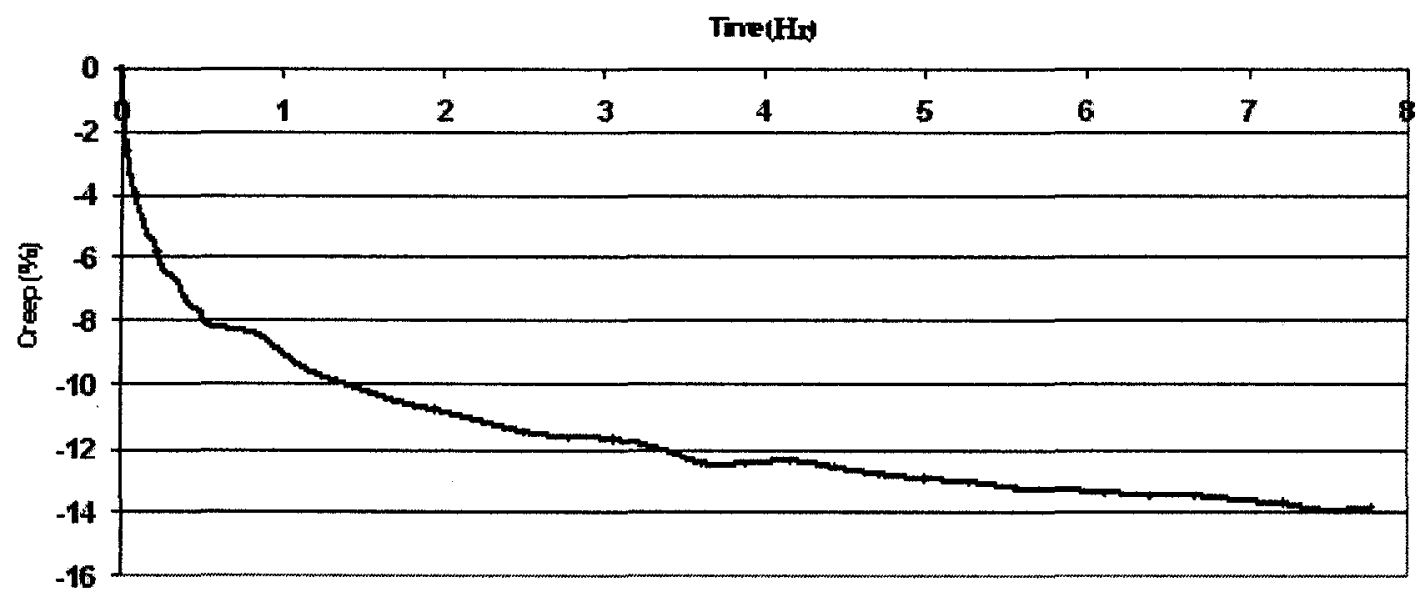

Figure 3.3 Behavior of strain rate over the 8 hour period in one of the motion segment tested for cyclic axial compression test at $0.1 \mathrm{~Hz}$

The behavior of creep in terms of percentage of the average disc height in one of the motion segment tested on cyclic axial compression at $0.1 \mathrm{~Hz}$ is shown in Figure 3.3. Creep which was calculated as the percentage deformation of the intervertebral disc was 
plotted versus the 8 hour time period. The rate of change of creep was high during the first two hours of the test. A gradual decrease of creep rate was observed as it proceeds to the end of the test. The load at which each test was performed depends in the failure stress of the motion segment from the same spine.

Energy density (ED) in the disc was calculated in terms of $\mathrm{KJ} / \mathrm{mm}^{3}$ at the end of 8 hour period ( 2600 cycles). All values were tabulated with respect to the specimen number and the level being tested. The deformation and energy values are calculated for the entire test period. Figure 3.3 shows that the vast majority of creep occurs well before the first 2 hours (60\% of the ultimate axial deformation) and that the rate of change in creep steadily decreases. A summary of results of the ultimate compression failure tests at 0.1 $\mathrm{Hz}$ is shown in the Table 3.3. 
Table 3.3

Summary of test results of cyclic compression tests at $0.1 \mathrm{~Hz}$ tabulated with respect to specimen number and level

\begin{tabular}{|c|c|c|c|c|}
\hline \multicolumn{5}{|c|}{ CYCLIC COMPRESSION TESTS $0.1 \mathrm{~Hz}$} \\
\hline Specimen \# & F740 & M1915 & F1914 & F741 \\
\hline Level & $\mathrm{T12} / \mathrm{L} 1$ & $\mathrm{~L} 1 / \mathrm{L} 2$ & $\mathrm{~T} 11 / \mathrm{T} 12$ & $\mathrm{~T} 10 / \mathrm{T} 11$ \\
\hline Frequency & 0.1 & 0.1 & 0.1 & 0.1 \\
\hline Average Disc Height(mm) & 9.916667 & 14.46666667 & 9.15 & 5.26667 \\
\hline Average Disc Height After Preload(mm) & 8.4795269 & 13.46013837 & 7.7300844 & 4.1499351 \\
\hline Disc Deformation during Preload(inm) & 1.4371401 & 1.0065283 & 1.4199156 & 1.1167349 \\
\hline Actuator Axial at 100th cycle (min) & 1.936650 & 1.760960 & 1.785074 & 1.385467 \\
\hline Disc Height at 100th cycle (mm) & 7.980017 & 10.590737 & 7.392485 & 3.881233 \\
\hline$\%$ Disc Deformation at 100 th cycle $(\%)$ & -5.890772 & -18.154788 & -4.367348 & -6.474843 \\
\hline Actuator Axial at 500th cycle (mm) & 2.374152 & 1.330348 & 2.170903 & 1.530152 \\
\hline Disc Height at 500th cycle (mm) & 7.542516 & 11.021349 & 7.006656 & 3.736548 \\
\hline$\%$ Disc Deformation at 500 th cycle & -11.050279 & -14.827021 & -9.358604 & -9.961296 \\
\hline Actuator Axial at 2600 th cycle (mm) & 3.139 & 2.684 & 2.901 & 1.685 \\
\hline Disc Height at 2600th cycle (mu) & 6.778 & 11.782 & 6.249 & 3.581 \\
\hline$\%$ Disc Deformation at 2600 th cycle & -20.069 & -18.554 & -19.163 & -13.698 \\
\hline Energy at 100 cycles $(\mathrm{KJ})$ & 3399.320 & 2283.661 & 460.152 & 575.327 \\
\hline Energy at 500 cycles $(\mathrm{KJ})$ & 12542.538 & 2977.603 & 1522.503 & 2009.552 \\
\hline Energy at 2600 cycles (KJ) & 65109.267 & 70489.655 & 7152.215 & 10290.355 \\
\hline Area $\left(\operatorname{Mr}{ }^{\wedge}\right)(\min / 2)$ & 1092.180 & 1852.645 & 1334.242 & 1190.989 \\
\hline Volume of the Disc $\left(\mathrm{mm}^{\wedge} 3\right)$ & 9261.170 & 24936.858 & 10313.807 & 4942.528 \\
\hline ED at 100 cycles $\left(\mathrm{KJ} / \mathrm{mm}^{\wedge} 3\right)$ & 0.367 & 0.092 & 0.045 & 0.116 \\
\hline ED at 500 cycles $\left(\mathrm{KJ} / \mathrm{mm}^{\wedge} 3\right)$ & 1.354 & 0.119 & 0.148 & 0.407 \\
\hline ED at 2600 cycles $\left(\mathrm{KJ} / \mathrm{mmm}^{\wedge} 3\right)$ & 7.03035027 & 2.826725601 & 0.6934603 & 2.08200247 \\
\hline
\end{tabular}


The mean energy density was calculated for all the motion segments tested for cyclic axial compression. A graph was plotted between the ED with respect to time ( $\mathrm{Hr})$.

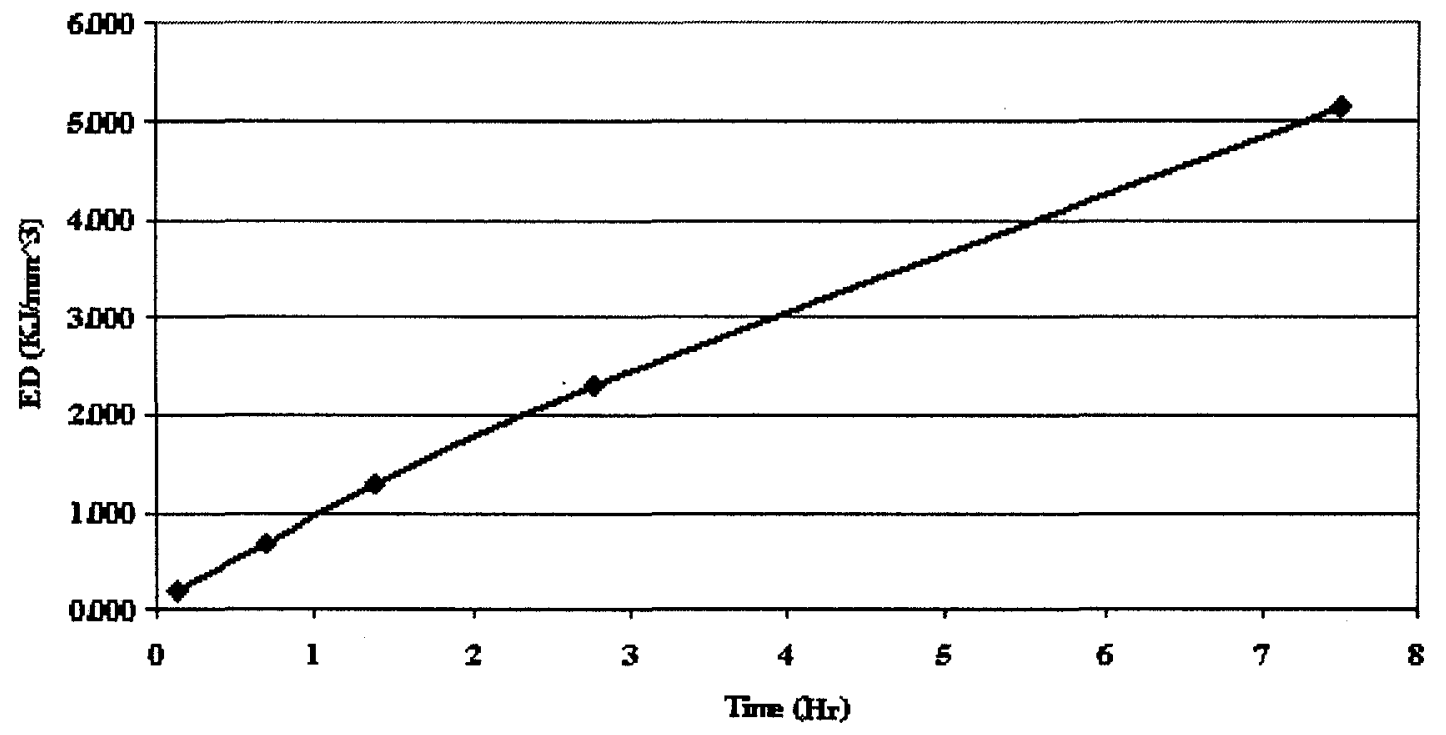

Figure 3.4 Behavior of cumulative energy density $\left(\mathrm{KJ} / \mathrm{mm}^{3}\right)$ over 8 hour time period in cyclic axial compression tests at $0.1 \mathrm{~Hz}$

Energy density of the motion segments tested under cyclic axial compression exhibited a linear relationship with time period. During compression energy was induced into the intervertebral disc. When compressive force on the motion segment was relived, a portion of energy was dissipated from the disc. The accumulated energy dissipated was calculated during the test. The linearity of the ED behavior is shown in Figure 3.4. 


\subsubsection{Cyclic Axial Compression Test Results at $0.2 \mathrm{~Hz}$}

The $0.2 \mathrm{~Hz}$ cyclic axial compression test was performed on four motion segments oriented at their neutral angles (Table 2.2). The segments were loaded with a maximum force equal to one-half of the failure force measured from the axial compression failure test on a motion segment from the same spine. Other than the frequency and segment specific load, the procedure was identical to that for the $0.1 \mathrm{~Hz}$ tests. Testing was performed for a period of 8 hours (approximately 5400 cycles). Creep, as a percentage of the average disc height, is plotted versus time.

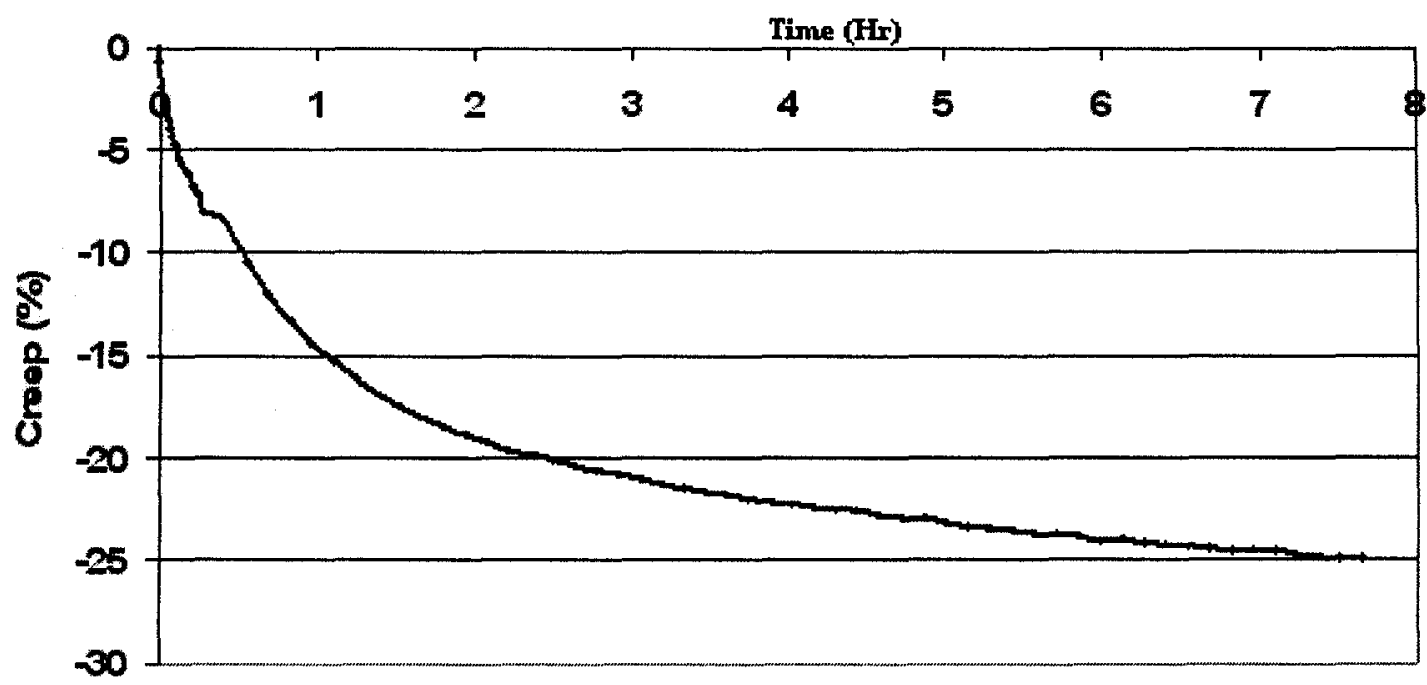

Figure 3.5 Creep of the intervertebral disc during cyclic axial compression test at $0.2 \mathrm{~Hz}$

The behavior of creep as percentage of the average disc height in one of the motion segment tested on cyclic axial compression at $0.2 \mathrm{~Hz}$ is shown in Figure 3.5. A gradual decrease of creep rate was observed as it proceeds to the end of the 8 hour period. Similar behavior of creep was observed in cyclic axial compression tests at $0.1 \mathrm{~Hz}$. Hence, cyclic axial compression tests both at $0.1 \mathrm{~Hz}$ and $0.2 \mathrm{~Hz}$ show a vast majority of creep during the early stages of the experiment. 
Energy density (ED) in the disc was calculated in terms of $\mathrm{KJ} / \mathrm{mm}^{3}$ at the end of the 8 hour period (5400 cycles) as well as after cycles 100 and 500. All values are tabulated with respect to the specimen number and the level being tested. Graph 3.5 shows that the vast majority of creep occur well before the first 500 cycles, and that the creep rate steadily decreases. A summary of the results from the ultimate compression failure tests at $0.2 \mathrm{~Hz}$ is shown in Table 3.4 .

Table 3.4

Summary of test results of cyclic axial compression at $0.2 \mathrm{~Hz}$ tabulated with respect to the specimen and level

\begin{tabular}{|c|c|c|c|c|}
\hline \multicolumn{5}{|c|}{ CYCLIC COMPRESSION TESTS $0.2 \mathrm{~Hz}$} \\
\hline Specimen \# & $\mathrm{M} 737$ & M738 & M739 & F741 \\
\hline Level & $\mathrm{L} 4 / \mathrm{LS}$ & T10/T11 & T8/T9 & LA/L5 \\
\hline Frequency & 0.2 & 0.2 & 0.2 & 0.2 \\
\hline Average Disc Height(mu) & 12.08333 & 7.71667 & 6.4333 & 10.333 \\
\hline Average Disc Height After Preload(rnm) & 10.8249944 & 6.4173257 & 4.992748 & 7.5316816 \\
\hline Disc Deformation during Preload(mun) & 1.2583356 & 1.2993443 & 1.440552 & 2.8013184 \\
\hline Actuator Axial at 100 (mm) & 1.688617 & 1.791964 & 2.157123 & 3.231930 \\
\hline Disc Height at 100 (mm) & 10.394378 & 5.924706 & 4.276210 & 7.101070 \\
\hline$\%$ Disc Deformation at $100(\%)$ & -3.977980 & -7.676405 & -14.351578 & -5.717337 \\
\hline Actuator Axial at $500(\mathrm{~mm})$ & 2.126119 & 2.257025 & 2.704861 & 3.703881 \\
\hline Disc Height at $500(\mathrm{~mm})$ & 9.956877 & 5.459645 & 3.728472 & 6.629120 \\
\hline$\%$ Disc Deformation at $500(\%)$ & -8.019569 & -14.923361 & -25.322251 & -11.983540 \\
\hline Actuator Axial at $5400(\mathrm{~mm})$ & 3.852 & 3.793 & 3.969 & 4.679 \\
\hline Disc Height at $5400(\mathrm{~mm})$ & 8.231 & 3.923 & 2.464 & 5.654 \\
\hline$\%$ Disc Deformation at $5400(\%)$ & -23.960 & -38.865 & .50 .645 & -24.928 \\
\hline Energy at 100 cycles (KJ) & 9985.321 & 9839.014 & 29472.406 & 725.362 \\
\hline Energy at 500 cycles $(\mathrm{KJ})$ & 35373.208 & 37089.264 & 119362.842 & 2461.307 \\
\hline Energy at 5400 cycles (KJ) & 271916.007 & 166917,289 & 1230750.92 & 20036.124 \\
\hline $\operatorname{Area}\left(\Pi r^{\wedge} 2\right)\left(\mathrm{Imm}^{\wedge} 2\right)$ & 2881.459 & 1495.896 & 1425.883 & 1691.611 \\
\hline Volume of the Disc $\left(\mathrm{mm}^{\wedge} 3\right)$ & 31191.780 & 9599.653 & 7119.074 & 12740.679 \\
\hline ED at 100 cycles $\left(\mathrm{KJ} / \mathrm{Mmn}^{\wedge} 3\right)$ & 0.320 & 1.025 & 4.140 & 0.057 \\
\hline ED at 500 cycles (KJ/mm 3 ) & 1.134 & 3.864 & 16.767 & 0.193 \\
\hline ED at $5400 \mathrm{cycles}\left(\mathrm{KJ} / \mathrm{mm}^{\wedge} \mathrm{3}\right)$ & 8.718 & 17.388 & 172.881 & 1.573 \\
\hline
\end{tabular}




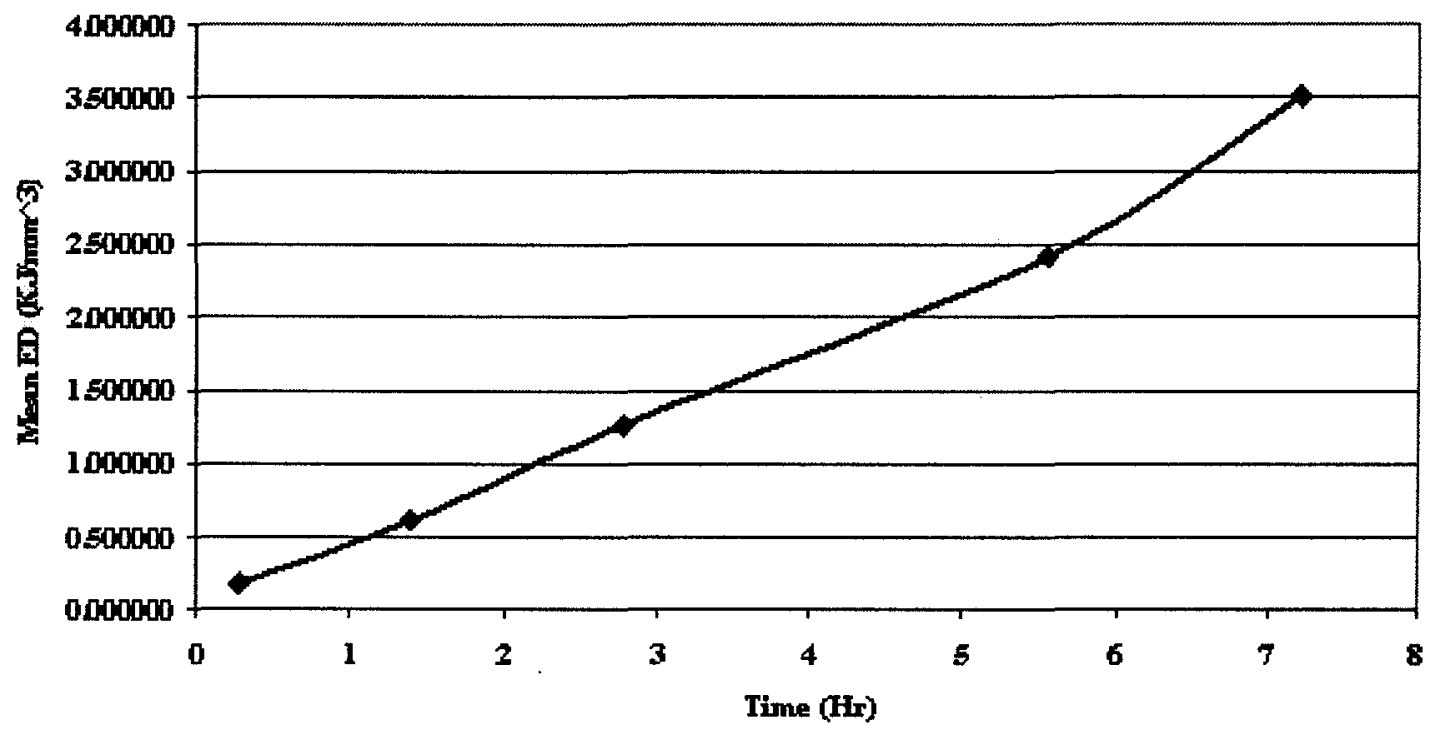

Figure 3.6 Behavior of mean energy density versus time ( $\mathrm{Hr})$ in cyclic axial compression tests at $0.2 \mathrm{~Hz}$

Similar to the ED characteristics of motion segments during cyclic axial compression tests at $0.1 \mathrm{~Hz}$, energy density exhibits a linear increase of energy in the intervertebral disc over the 8 hour time period. Mean values of ED were taken from all cyclic compression tests at $0.2 \mathrm{~Hz}$. A gradual increase of ED over time was observed in the motion segment. The behavior is shown in Figure 3.6 which was very different from the creep behavior.

\subsection{Ultimate Bending Test Results}

The ultimate bending test was performed on three motion segments, two from the lumbar level and one from the thoracic level. Using the moment arm arrangement, a maximum bending moment of $40 \mathrm{Nm}$ was applied to the motion segment at a rate of 0.2 deg/sec. The angular deformation and moment were constantly monitored. The energy dissipation of the intervertebral disc was calculated using the formula: 


$$
E=0.5 *\left(M_{2}+M_{1}\right) *\left(A_{2}-A_{1}\right)+E_{\text {initial }}
$$

where $M_{1}$ and $M_{2}$ are the bending moments at the beginning and end of the load step and $A_{1}$ and $A_{2}$ are the corresponding rotational deformations. The energy dissipated and angular deformation at $20 \mathrm{Nm}$ and $40 \mathrm{Nm}$ are shown in Table 3.5.

Table 3.5

Summary of results of ultimate bending tests tabulated with respect to the specimen and level tested.

\begin{tabular}{|l|c|c|c|c|c|}
\hline \multicolumn{5}{|c|}{ ULTIMATE BENDING TESTS } \\
\hline Specimen \# & M737 & M738 & M738 & M738 & M739 \\
\hline Level & T12/L1 & T12/L1 & T12/L1 & T12/L1 & T10/T11 \\
\hline Test & & Trial 1 & Trial 2 & Trial 3 & \\
\hline Angular Deformation(Deg) at 20Nm & -3.7712 & -9.2508 & -11.264 & -11.792 & -7.7711 \\
\hline Angular Deformation(Deg) at 40Nm & -7.5745 & -16.083 & -16.651 & -17.138 & -12.625 \\
\hline Energy(KJ) at 20Nm & 44.4661 & 79.2159 & 104.201 & 103.44 & 38.3878 \\
\hline Energy(KJ) at 40Nm & 159.234 & 288.847 & 264.684 & 262.54 & 186.391 \\
\hline Resulting Moment At End of the Test & $59.3 \mathrm{Nm}$ & $41 \mathrm{Nm}$ & $44.61 \mathrm{Nm}$ & $40.85 \mathrm{Nm}$ & $\mathbf{4 8 . 9 4 1 6}$ \\
\hline Resulting Ang Deformation(Deg) At End of the Test & -11.9033 & -16.54 & -17.788 & -17.454 & -19.994 \\
\hline Resulting Energy At End of the Test & $\mathbf{3 7 4 . 3 6 8}$ & 307.445 & 313.009 & 275.238 & 524.404 \\
\hline
\end{tabular}

An angular deformation up to $20 \mathrm{deg}$ was achieved. Motion segments did not show any signs of failure with pure flexion loads up to $40 \mathrm{Nm}$ which was well beyond the flexion load levels experienced in-vivo.

\subsection{Cyclic Bending Test Results}

Five motion segments (four from the lumbar region) were tested for a cyclic bending moment of $20 \mathrm{Nm}$ at a frequency of $0.2 \mathrm{~Hz}$. Angular deformation (deg) and 
moment $(\mathrm{Nm})$ were constantly monitored throughout the experiment. The variation in angular deformation with respect to the number of cycles is shown in graph 3.7.

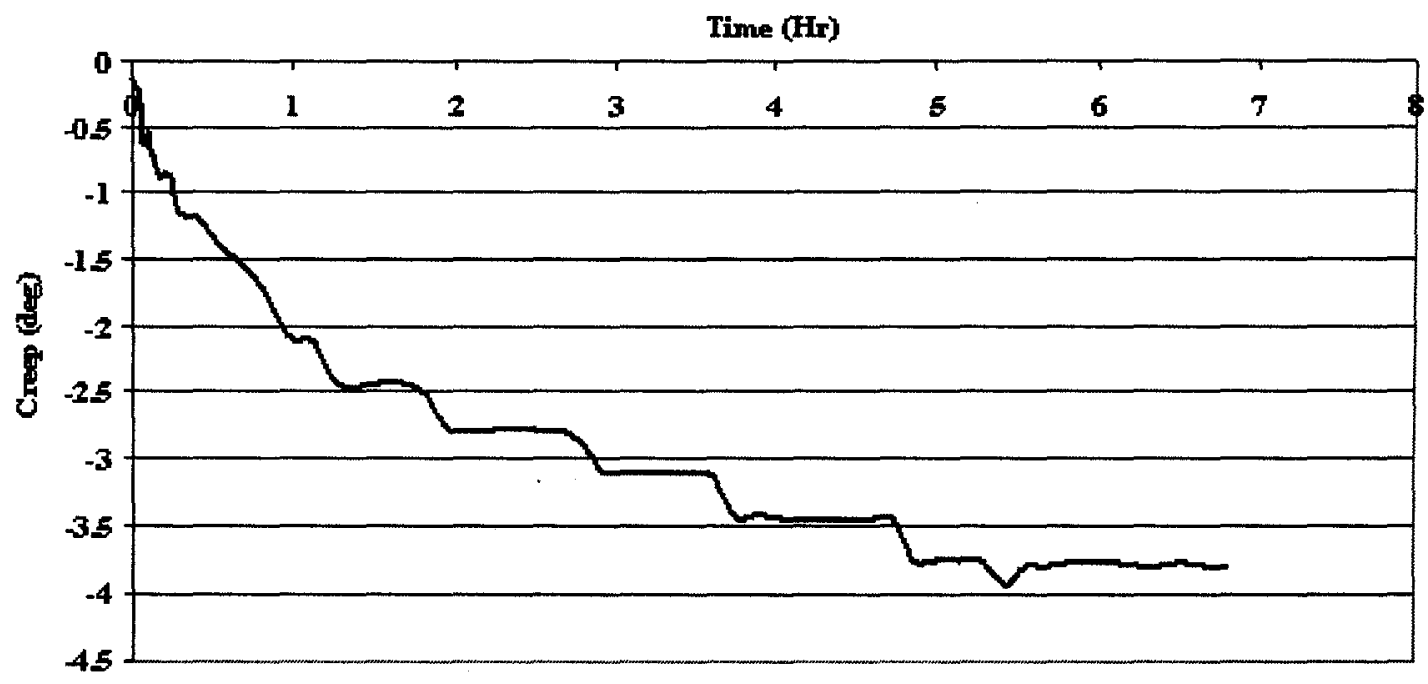

Figure 3.7 Creep in terms of angular deformation (deg) versus time ( $\mathrm{Hr}$ ) for one of the motion segments tested for cyclic bending at $20 \mathrm{Nm}$.

The behavior was similar to the cyclic axial compression tests where the vast majority of angular deformation occurs in the first 100 cycles and the rate of change of the angular deformation gradually decreases. A summary of the angular deformation (deg) for the five motion segments tested is shown in Table 3.6. 
Table 3.6

Summary of the resultant angular deformation of the disc at 4900 cycles and end of the test in cyclic bending tests.

\begin{tabular}{|l|c|c|c|c|c|}
\hline \multicolumn{7}{|c|}{ CYCLIC FLEXION TESTS } \\
\hline Specimen \# & $\mathrm{M} 737$ & $\mathrm{M} 737$ & $\mathrm{M} 738$ & $\mathrm{M} 739$ & F740 \\
\hline Level & $\mathrm{T} 10 / \mathrm{T} 11$ & $\mathrm{~L} 2 / \mathrm{L} 3$ & $\mathrm{~L} 2 \mathrm{~L} 3$ & $\mathrm{~T} 12 / \mathrm{L} 1$ & $\mathrm{~L} 4 / \mathrm{L} 5$ \\
\hline Frequency & 0.2 & 0.2 & 0.2 & 0.2 & 0.2 \\
\hline Resulting Deformation(Deg) at End of 4900 cycles & -3.2545 & -2.1176 & -3.678 & -3.7894 & -2.9647 \\
\hline Resulting Deformation(Deg) at End of the Test & -3.2545 & -2.1176 & -4.0124 & -4.1015 & -5.3275 \\
\hline
\end{tabular}

\subsection{Summary}

A total of 27 spine motion segments were tested in compression and flexion series. In order to analyze the results, applied force (or moment) and axial (or angular) deformation from the MTS was extracted for both individual loading cycles and cumulatively, from which the damage measures of creep and energy dissipation were calculated. Table 3.9 shows the breakdown of the gender, age, and number of motion segments tested in each series. 
Table 3.7

Summary of spine motion segments tested, the average age of the specimens tested, number of males, number of females and total number of spines tested.

\begin{tabular}{|c|c|c|c|}
\hline $\begin{array}{c}\text { \# of } \\
\text { Specimens } \\
\text { Tested }\end{array}$ & \multicolumn{2}{|c|}{ Ultimate Axial Compression Test } & Ultimate Bending Test \\
\hline Thorax & \multicolumn{2}{|c|}{9} & 1 \\
\hline Lumbar & \multicolumn{2}{|c|}{0} & 3 \\
\hline Failed & \multicolumn{2}{|c|}{9} & 0 \\
\hline Total & \multicolumn{2}{|c|}{9} & 4 \\
\hline & \multicolumn{2}{|c|}{ Cyclic Compression } & Cyclic Moment \\
\hline $\begin{array}{c}\text { \# of } \\
\text { Specimens } \\
\text { Tested }\end{array}$ & $0.1 \mathrm{~Hz}$ & $0.2 \mathrm{~Hz}$ & $0.2 \mathrm{~Hz}$ \\
\hline Thorax & 2 & 2 & 1 \\
\hline Lumbar & 2 & 2 & 4 \\
\hline \multirow[t]{2}{*}{ Total } & 4 & 4 & 5 \\
\hline & $\begin{array}{c}\text { Specimens } \\
\text { Tested }\end{array}$ & & \\
\hline Average age & 76 & & \\
\hline \# Males & 4 & & \\
\hline \# Females & 3 & & \\
\hline Total \# & 7 & & \\
\hline
\end{tabular}

The behavior of the intervertebral disc during cyclic compression tests were studied and can be explained by a hysteresis chart showing the changes in stress-strain. Application of cyclic compressive force on the intervertebral disc results in deformation of the disc. The stress applied during cycling was calculated in MPa. The deformation of the disc at the end of each cycle was noted and converted into percentage deformation considering the average disc height as reference. Hence the changes in stress-strain relationship were plotted. 


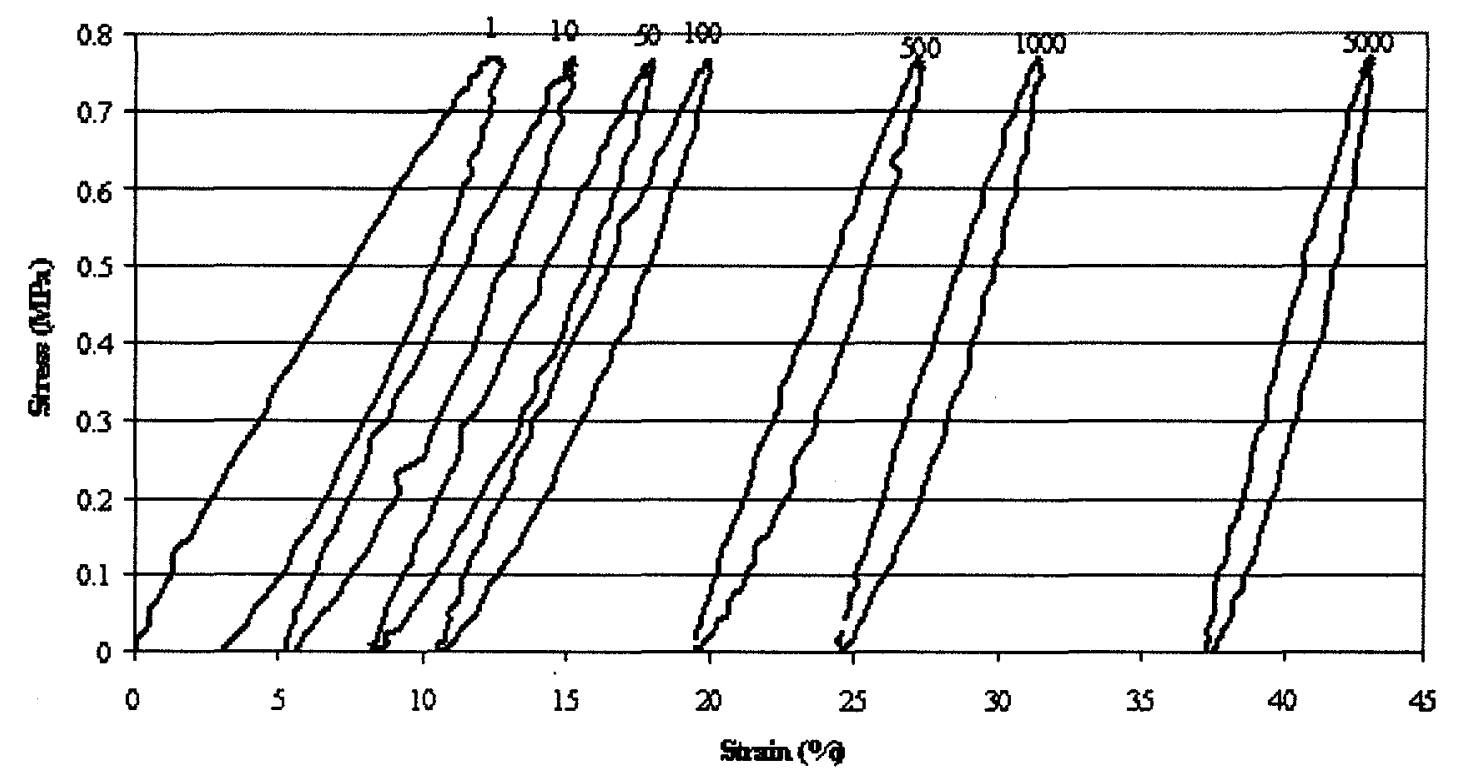

Figure 3.8 Changes in stress-strain relationship of one of the motion segments under cyclic compression test at cycles $1,10,50,100,500,1000$ and 5000

The amount of stress applied throughout the experiment was constant at a fixed frequency of 0.1 or $0.2 \mathrm{~Hz}$. The application of stress on the intervertebral disc of the motion segment results in strain. The strain in the disc was highest in the first cycle and gradually decreases as it reaches the end cycle. The area under each cycle represents the amount of energy dissipated by the disc. The energy dissipated by the disc decreases over the 8 hour period. The stiffness changes in the disc can also be observed as the slope of each curve. 


\subsection{Discussion}

The purpose of this study was to investigate the importance of specimen orientation and load frequency on the properties of the human thoracolumbar motion segments, as well as to explore the use of creep and energy dissipation as damage measures. Baseline results were obtained by testing spinal segments to failure in both axial compression and flexion. The differences in behavior for two cyclic loading frequencies were observed and quantitative information on damage prediction using creep and energy density as measures were developed. The results are discussed in brief in the following sections.

\subsubsection{Influence of orientation}

All spinal motion segments were oriented at neutral angles in this study except for three motion segments that were tested without orientation in the ultimate axial compression failure test. The results show an increase in failure force for motion segments without orientation. When testing oriented motion segments under axial compression, displacement of the MTS actuator applies axial as well as shear force on the motion segments. Displacement of the MTS actuator on motion segments without orientation exerts only axial force on the motion segments. Since shear force was not monitored in this study, there is a drop in axial failure force when motion segments are oriented at the neutral angle, likely due to the interaction between the axial and shear forces. 


\subsubsection{Influence of frequency}

All cyclic axial compression tests were performed at two frequencies, $0.1 \mathrm{~Hz}$ and $0.2 \mathrm{~Hz}$. Results from the cyclic axial compression tests show a change in material properties of the intervertebral disc according to the loading frequency. For normalization of data, the percentage deformation of the intervertebral disc, relative to the average initial disc height, was considered for analysis. The average percentage deformation of the disc was calculated for cycles 100,500 and, 2000 for all cyclic compression tests and is shown in Figure 3.8. There was an increase in deformation of the disc for a loading frequency of $0.2 \mathrm{~Hz}$ as compared to a loading frequency of $0.1 \mathrm{~Hz}$.

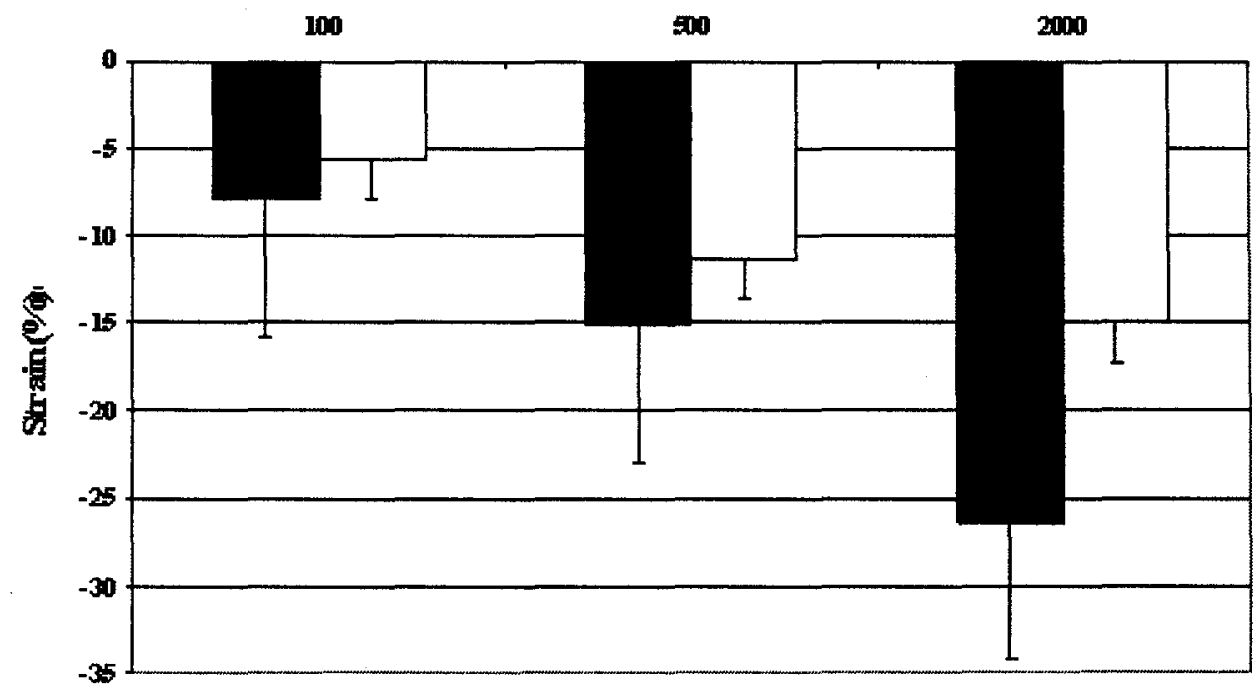

Q $0.3 \mathrm{HzO} 0.1 \mathrm{~Hz}$

Figure 3.9 Frequency dependence of Strain (\%) of four specimens at cycles 100, 500 and 2000

Similarly the energy density $\left(\mathrm{KJ} / \mathrm{mm}^{3}\right)$ was calculated at cycles 100,500 and 2000. Energy density was higher in motion segments tested at $0.2 \mathrm{~Hz}$ compared to motion segments tested at $0.1 \mathrm{~Hz}$ for cyclic axial compression. 


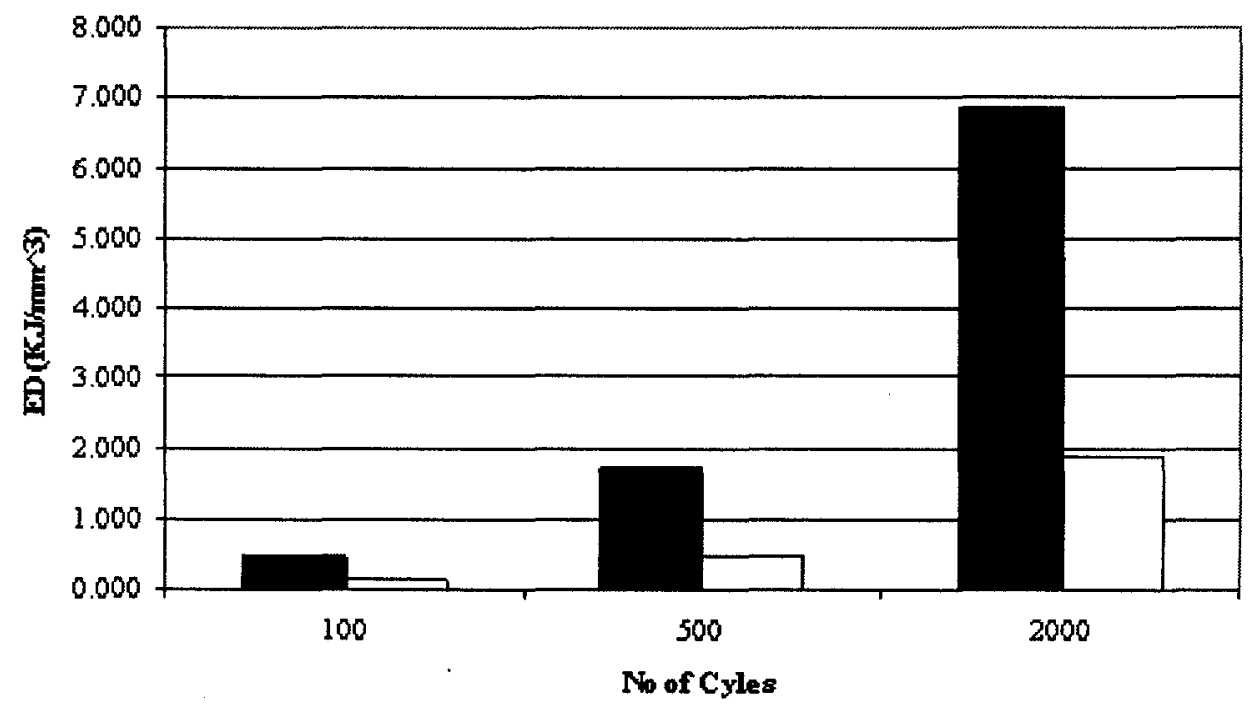

$0.2 \mathrm{~Hz} \square 0.1 \mathrm{~Hz}$

Figure 3.9 Frequency dependence of energy density at cycles 100, 500 and 2000

\subsubsection{Creep as a damage measure}

Creep was observed to occur over time in cyclic tests with the maximum creep rate observed during the first two hours (Figure 3.3, 3.5). Creep was also measured in terms of angular displacement during the cyclic bending tests.

The vast majority of creep $(60 \%)$ was observed during the first two hours of cycling (Figure 3.7). Creep rate was largest during the initial stages, which illustrates the importance of the early stages of loading in determining the ultimate response of the spinal segments to prolonged cycling. But saturation of creep was observed at the end of the 8 hour period. 


\subsubsection{Energy Dissipation as damage measure}

Cumulative energy density of the motion segments through the entire 8 hour period of cyclic loading was studied. A constant increase of cumulative energy density was observed over time in cyclic axial compression tests. The graph between average cumulative energy density versus time was almost linear, showing the linearity of energy density when calculated as a cumulative measure.

\subsubsection{Ultimate bending tests}

Motion segments did not exhibit any sign of failure during the application of a maximum bending of $40 \mathrm{Nm}$ during the moment failure tests. Even for loads well beyond those experienced in in-vivo, it was not possible to cause failure of intact motion segments with virtually pure bending. 


\section{CHAPTER 4}

\subsection{CONCLUSION}

The aim of this research was to determine the material properties of the intervertebral disc and investigate the feasibility of using creep and energy dissipation as damage measures to quantify the effect of repetitive loading on the thoracolumbar spine. Literature review of the material properties of the intervertebral disc under repetitive loads uncovered the voids and problems listed below.

1. Unrealistic spinal segment positioning during testing.

2. Usage of the number of cycles to failure and force as damage measures which do not account for load changes between cycles or have no cumulative component.

3. Frequency of testing was not representative of typical normal activities.

Hence in this study, testing was done orienting the spine motion segments to their neutral angle at frequencies of 0.1 and $0.2 \mathrm{~Hz}$. There was an increase in axial failure force in motion segments of the thoracic level when the segments were tested without orientation compared to the specimens tested with orientation during ultimate axial compression. Intact motion segments do not show any signs of failure even for loads well beyond those normally experienced in in-vivo, when subjected to bending loads. 
Quantitative information on damage prediction using creep and energy dissipation as measures was obtained. For the cyclic compression and flexion tests, the vast majority of creep occurred during the first two hours of cycling. The rate of change of creep gradually decreased over time and eventually became relatively constant. A linear increase of cumulative energy density was observed over the 8 hour period. Rate of change of the cumulative energy density was relatively constant in the cyclic axial compression data. Hence the conclusions of this study are as follows:

1. The mechanical properties of the disc depend on the orientation of the motion segments at neutral angle. Orientation might have little or no effect during flexion tests, but during axial compression, compressive forces on the spine motion segment are distributed through the intervertebral discs depending on its orientation.

2. Creep rate was largest during the initial cycling leading to over $60 \%$ of the total creep occurring during the first 30 minutes and minimum change at the end period. Its saturation over time shows it would have a relatively constant value well before the failure of the motion segment. Hence, creep would not be a good damage measure.

3. The behavior of cumulative energy dissipation in the intervertebral disc linearly increases over time. The comparison chart of the cumulative energy density at failure to that at the end of 8 hour cyclic compression loads in Figure 4.1 show a 
possibility correlating the cumulative energy density at failure to that at cyclic loads.

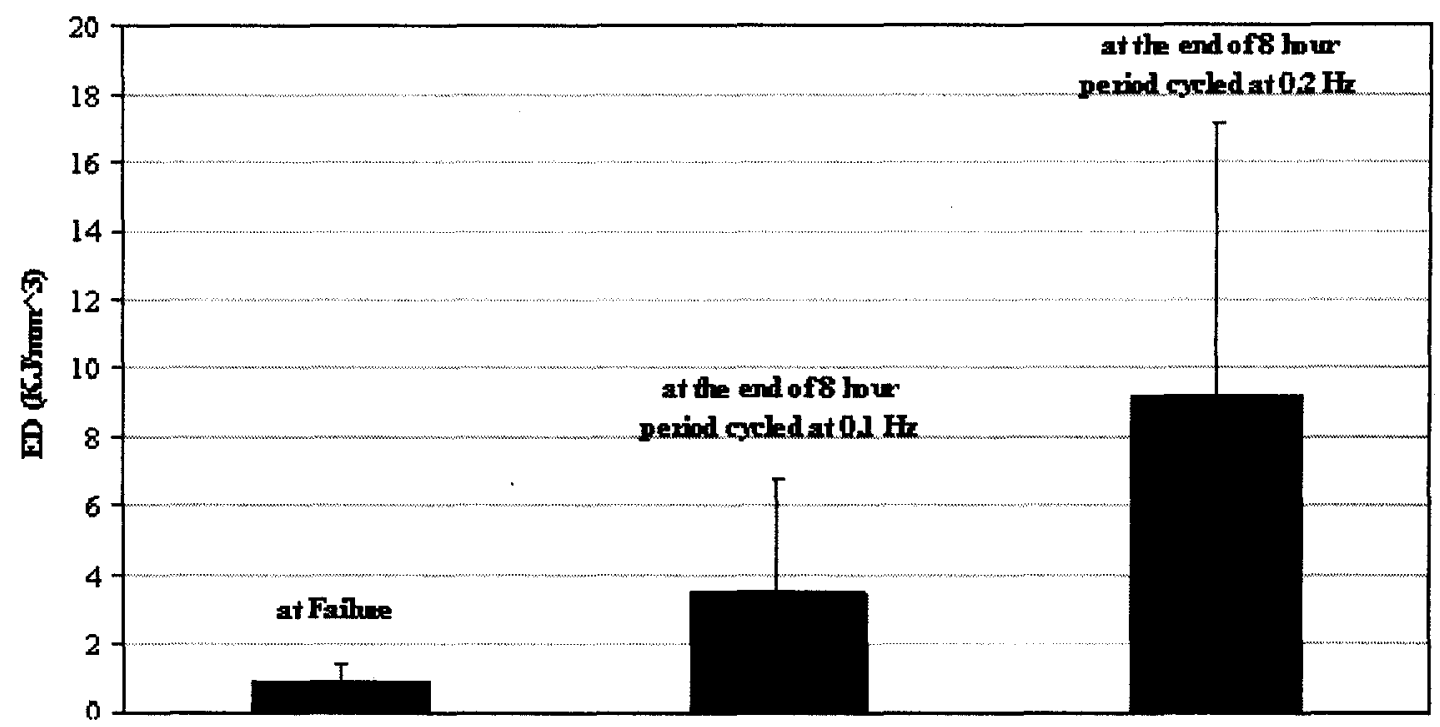

Figure 4.1 Energy density comparison chart of 12 motion segments ( 3 from each spine) each tested for failure and cyclic compression

\subsection{Limitations and future research}

The bone density of the vertebrae was not considered in this study. Scanning for bone density would improve normalization of the data. Also, only sagittal plane behavior of the motion segments was studied and rotational components such as torque must be considered. The frequency dependence of energy dissipation and creep can be also studied in flexion as well as in axial compression as done in this study. In addition, the axial deformation of the disc could not be determined in the flexion series of testing. Determination of the axial deformation of the disc during repetitive loading of the motion segment would provide better insight into creep and energy dissipation. Finally, future research could also include age adjustment of the motion segments. 
Even though limitations were observed in this study, the importance of segment positioning was established. Material properties of the intervertebral disc were studied in detail. Creep and energy dissipation were successfully used as damage measures instead of cycles to failure from previous studies which had no account for load changes. This study was a significant step in understanding the behavior of the spine under repetitive loading and establishing damage measure for fatigue failure in the thoracolumbar spine. 


\section{REFERENCES}

1. Papageorgiou A.C., Croft P.R., Thomas E., Ferry S., Jayson M.1.V. and Silman A.J. (1996) Influence of previous pain experience on the episode influence of low back pain ; evidence from the South Manchester study. Pain 66: 181-185.

2. Snook, S. H., Campanelli, V. and Hart, J. W. 1978, A study of three preventive approaches tolow back injury, Journal of Orthopeadic Medicine, 20, $478 \pm 481$.

3. Sham ML, Zander T, Rohlmann A, Bergmann G. 2005 Nov, Effects of the rib cage on thoracic spine flexibility. Biomed Tech (Berl).;50(11):361-5.

4. Nordin, M. \& Frankel, V.11. 1989. Basic blomechanies of the musculoskeletal system. 2nd Ed. Lea \& Febiger, Philadelphlap 104, 202.

5. Bogduk N (1997): Clinical Anatomy of the Lumbar Spine and Sacrum. Edinburgh: Churchill Livingstone, pp 1-261.

6. White A, Panjabi M 1990: Clinical Biomechanics of the Spine. second edition, J. B. Lippincott and co., pps. 235-255,

7. Farfan, H. F. (1973). Mechanical Disorders of the Low Back. Lea and Febiger, Philadelphia

8. Carter. D R and Hayes. W C (1977) The compressive behavior of bone as a two-phase porous structure. J. Bone. Jt Sury. 58A, 954-962. 
9. Adams, M.A., Hutton, W.C., Stott, JR.R. (1980) The resistance to flexion of the lumbar intervertebral joint. Spine, 5:245-252.

10. Roberts, S., Urban, J.P.G., Evans, E.H., Eisenstein, S.M. (1996) Transport properties of the human cartilage endplate in relation to its composition and calcification. Spine, 52 21:415-420.

11. Yoganandan, N., Larson, S. J., Pintar, F., Gallagher, M., Reinartz, J., and Droese, K. (1994) Intervertebral pressure changes caused by spinal microtrauma, Neurosurgery $35: 415-421$.

12. Brinckmann, P., Biggemann, M., Hilweg, D. (1988) Fatigue fracture of human lumbar vertebrae. Clinical Biomechanics Suppl. 1:S1-S23.

13. Adams, M.A., McNally, D.S., Wagstaff, J., Goodship, A. E. (1993) Abnormal stress concentration in lumbar intervertebral discs following damage to the vertebral body: A cause of disc failure. Eur. Spine Journal, 1: 214-221.

14. Adams, M.A., Freeman, B.J.C., Morrison HP, Nelson IW, Dolan P (2000) Mechanical initiation of intervertebral disc degeneration. Spine 25:16251636.

15. Brinckmann, P., Frobin, W., Hierholzer, E., Horst, M. (1983) Deformation of the vertebral end-plate under axial loading of the spine. Spine, 8:851-856.

16. Holmes, A.D., Hukins, D.W.L. (1993) Response of the end-plate to compression of the spine. European Spine Journal 2:16-21.

17. Bogduk, N. (1976) The anatomy of the lumbar intervertebral disc syndrome. The Medical Journal of Australia 1:878-881. 
18. Buckwalter, J.A. (1995) Aging and degeneration of the human intervertebral disc. Spine 20:1307-1314.

19. Grieve, G.P., Common vertebral joint problems, Churchill Livingstone, Edinburgh New York ;, 1981, xiv, 576 pp.

20. Kazarian LE 1975 Creep characteristics of the human spinal column. Orthopaedic Clinics of North America \&(1):3-18

21. Chaffin, D.B., Park, K.S. (1973) A longitudinal study of low back pain as associated with occupational weight lifting factors. Am Ind Hyg Assoc Journal, 34: 513-525.

22. Callaghan, J.P., McGill, S.M. (2001) Intervertebral disk herniation: studies on a porcine model exposed to highly repetitive flexion/extension motion with compressive force. Clinical Biomechanics, 16: 28-37.

23. Davis, K.G., Marras, W.S., and Waters, T.R. (1998) "Reduction of Spinal Loads Through the Use of Handles,"Ergonomics, 41(8), 1155-1168.

24. S. Gallagher, W.S. Marras, . and K.G. Davis 2002. Effects of Posture on Dynamic Back Loading During a Cable Lifting Task. Ergonomics, 45(5):380398.

25. Schultz, A.B., Warwick, D.N., Berkson, M.H., Nachemson, A. (1979) Mechanical properties of human lumbar spine motion segment . Part I: Responses in flexion, extension, lateral bending and torsion. J Biomech Engng 101:46-52.

26. Panjabi, M.M., Krag, M.H., Chung, T.Q. (1984) Effects of disk injury on mechanical behavior of the human spine. Spine 9:707-713. 
27. J.C. Lotz, J.R. Chin. Intervertebral disc cell death is dependant on the magnitude and duration of spinal loading. Spine, 25(12): 1477-1483, 2000.

28. Adams, M.A., Freeman, B.J.C., Morrison HP, Nelson IW, Dolan P (2000) Mechanical initiation of intervertebral disc degeneration. Spine 25:16251636.

29. Buckwalter, J.A. (1995) Aging and degeneration of the human intervertebral disc. Spine 20:1307-1314.

30. Frymoyer, J., Pope, M., Clement, J., Wilder, D.,MacPherson, B., \& Ashikaga, T. (1983). Risk factors in low back pain: an epidemiologic survey. J Bone Joint Surg. Am. 65:213-218.

31. Gallagher S, Marras WS, Davis KG, Kovacs K. Effects of posture on dynamic back loading during a cable lifting task.Ergonomics. 2002 Apr 15;45(5):38098.

32. Marras, W., Lavender, S., Leurgans, S., Rajulu, S., Allread, W., Fathallah, F. and Ferguson, S. 1993, The role of dynamic three-dimensional trunk motion in occupationally-related low back disorders, Spine, 18, $617-628$.

33. Punnet, L., Fine, L., Keyserling, W., Herrrin, G. and Chaffin, D. 1991, Back disorders and nonneutral trunk postures of automobile assembly workers, Scandinavian Journal of Work Environment and Health, 17, 337 - 345.

34. Panjabi MM, Oxland TR, Yamamoto I, Crisco JJ: Mechanical behavior of the human lumbar spine as shown by three-dimensional load-displacement curves. JBJS, 76-A(3):413-424, 1994. 
35. Keller TS, Spengler DM, Hansson TH. Mechanical behavior of the human lumbar spine. I. Creep analysis during static compressive loading. J Orthop Res. 1987;5(4):467-78.

36. Amonoo-Kuofi HS. Changes in the lumbosacral angle, sacral inclination and the curvature of the lumbar spine during aging. Acta Anat (Basel). 1992;145(4):373-7.

37. Aspden, R.M., 1989. The spine as an arch. A new mathematical model. Spine $14,266-74$.

38. Jorgensen, M. J., Marras, W. S., Gupta, P. and Waters, T. R., 2003a. The effect of torso flexion on the lumbar torso extensor muscle sagittal plane moment arms. The Spine Journal 3(5), 363-369.

39. Jorgensen, M. J., Marras, W. S. and Gupta, P., 2003b. Cross-sectional area of the lumbar back muscles as a function of torso flexion. Clinical Biomechanics $18(4), 280-286$.

40. Panjabi, M. M., Goel, V., Oxland, T., Takata, K., Duranceau, J., Krag, M., Price, M. (1992) Human lumbar vertebrae: quantitative three-dimensional anatomy, Spine, 17: 299. 306.

41. Pearcy, M.J., Tibrewal, S.B., 1984. Lumbar intervertebral disc and ligament deformations measured in-vivo. Clinical Orthopaedics and Related Research 191, 281-288.

42. Tibrewal SB, Pearcy MJ, Lumbar intervertebral disc heights in normal subjects and patients with disc herniation. Spine. 1985 Jun;10(5):452-4. 
43. Pearcy MJ, Tibrewal SB, Axial rotation and lateral bending in the normal lumbar spine measured by three-dimensional radiography.Spine. 1984 Sep;9(6):582-7

44. Nissan M, Gilad I, Dimensions of human lumbar vertebrae in the sagittal plane, J Biomech. 1986;19(9):753-8.

45. Gilad I, Nissan M, A study of vertebra and disc geometric relations of the human cervical and lumbar spine.Spine. 1986 Mar;11(2):154-7.

46. Lee YH, Chen YL, Regressionally determined vertebral inclination angles of the lumbar spine in static lifts. Clin Biomech (Bristol, Avon). 2000 Nov;15(9):672-7.

47. Yi-Lang Chen, Predicting the vertebral inclination of the lumbar spine, Ergonomics, 2000, VOL. 43, NO. 6, 744 \pm 751.

48. Lysell E, Motion in the cervical spine. An experimental study on autopsy specimens. Acta Orthop Scand. 1969;:Suppl 123:1.

49. Y-L Chen, Y-H Lee, A non-invasive protocol for the determination of Lumbosacral vertebral angle Clinical biomechanics Vol. 12 no.3 1997.

50. Frobin W, Brinckmann P, Leivseth G, Biggemann M, Reikeras O, Precision measurement of segmental motion from flexion-extension radiographs of the lumbar spine. Clin Biomech (Bristol, Avon). 1996 Dec;11(8):457-465. 
51. Patel M M, Gohil D V, Singel T C, Orientation of Superior Articular Facets from C3 to S1 Vertebrae, Journal of Anatomical Society of India, Vol. 53, No.2 (2004-07-2004-12)

52. Campbell-Kyureghyan N, Jorgensen M, Burr D, Marras W. The prediction of lumbar spine geometry: method development and validation. Clin Biomech (Bristol, Avon). 2005 Jun;20(5):455-64.

53. Pearcy M, Portek I, Shepherd J. Three-dimensional $x$-ray analysis of normal movement in the lumbar spine. Spine. 1984 Apr;9(3):294-7.

54. Harrison DE, Cailliet R, Harrison DD, et al. Centroid, Cobb or Harrison posterior tangents: which to choose for analysis of thoracic kyphosis? Spine 2001; 26:E227-E34.

55. Harrison DE, Janik TJ, Harrison DD, Cailliet R, Harmon SF, Can the thoracic kyphosis be modeled with a simple geometric shape? The results of circular and elliptical modeling in 80 asymptomatic patients. $J$ Spinal Disord Tech. 2002 Jun;15(3):213-20.

56. Zhang YM, Voor MJ, Wang M, Johnson JR, Intervertebral measurement of lumbar segmental motion with a new measuring device. Med Eng Phys. 1998 Mar; 20(2):139-48. 


\section{CURRICULUM VITAE}

\section{Sai Vikas Yalla}

\section{SUMMARY}

- One year experience as Jr. Engineer in ASHOINDIA Ltd.

- Project work in micro-controller based Waste Water Treatment

- In-plant training in Rein Calcining Ltd for a period of three months

- P.C.B Design and Manufacturing training in Life Line Circuits, India

- Dynamic leader and team builder with excellent oral and written communication skills

\section{EDUCATION}

M.S. (Aug'04-Jul'06)

B.E. (1999-2003)
Industrial Engineering, University of Louisville, KY Electronics and Instrumentation, Madras University, India

\section{ACHIVEMENTS}

- Best project award for Waste Water Treatment in Madras University, India

- Best poster presentation in Industrial Engineering Department in E-expo, University of Louisville, KY

- Travel Award for poster presentation in Injury Biomechanics Symposium at OHIO State University, $\mathrm{OH}$

\section{PROFESSIONAL MEMBERSHIPS}

- President of Human Factors and Ergonomics Society University of Louisville Student Chapter, University of Louisville, KY.

- President of Akhila Andhra Student Association, University of Louisville, KY.

- Vice-President of Indian Student Association, University of Louisville, KY.

- Secretary of Instrumentation Society Automation, St. Joseph's College Student Chapter, Madras University, India. 


\section{COMPUTER TOOLS}

Packages: Arena 8.0, Minitab.

Languages: C, Visual Basic (Microsoft Certified Professional), MATLAB, and HTML.

Microsoft

Office Suite: MS word, Excel, Power Point, Access, Front Page.

Operating

Systems: $\quad$ MS-DOS, Windows NT/2000, UNIX.

\section{WORK EXPERIANCE}

PRESENT RESEARCH ASSISTANT NOV'05-

- Designed loading fixture for spine specimen segmental positioning.

- Tested oriented spine motion segments to develop damage measures for fatigue failure under repetitive testing with MTS.

- Creep and energy dissipation were investigated as damage measures.

TEACHING ASSISTANT

JAN'06-AUG'06

- Graduate teaching assistant in Industrial Engineering Department for Human Performance and Work Design Lab.

INTERNSHIP ASHOINDIA LTD

AUG'03-JUL'04

- Worked as a Junior Engineer in waste water management

INTERNSHIP REIN CALCINING LTD MAY'01-JUL'01

- Worked in the calcining plant control systems and logistics department

\section{PRESENTATIONS}

- Poster presentation in Injury Biomechanics Symposium'06 at Ohio State University on "Cyclic testing of Human Lumbar Spine Motion Segments"

- Poster presentation in E-expo, University of Louisville, KY on "Design of a Loading Fixture for Spinal Segment Testing" 